University of Louisville ThinkIR: The University of Louisville's Institutional Repository

Electronic Theses and Dissertations

$12-2016$

\title{
Workplace spirituality and employee work intentions : examining the relationship and the mediating role of ethical leadership.
}

Paula F. Soder

Follow this and additional works at: https://ir.library.louisville.edu/etd

Part of the Educational Leadership Commons, and the Organization Development Commons

\section{Recommended Citation}

Soder, Paula F., "Workplace spirituality and employee work intentions : examining the relationship and the mediating role of ethical leadership." (2016). Electronic Theses and Dissertations. Paper 2569.

https://doi.org/10.18297/etd/2569

This Doctoral Dissertation is brought to you for free and open access by ThinkIR: The University of Louisville's Institutional Repository. It has been accepted for inclusion in Electronic Theses and Dissertations by an authorized administrator of ThinkIR: The University of Louisville's Institutional Repository. This title appears here courtesy of the author, who has retained all other copyrights. For more information, please contact thinkir@louisville.edu. 
WORKPLACE SPIRITUALITY AND EMPLOYEE WORK INTENTIONS:

EXAMINING THE RELATIONSHIP AND THE MEDIATING ROLE OF ETHICAL

\title{
LEADERSHIP
}

\author{
By \\ Paula F. Soder \\ B.S., Universidade de Santa Cruz do Sul, 2002 \\ M.S., Marshall University, 2005
}

A Dissertation

Submitted to the Faculty of the

College of Education and Human Development of the University of Louisville in Partial Fulfillment of the Requirements

for the Degree of

Doctor of Philosophy

in Educational Leadership and Organizational Development

Department of Educational Leadership, Evaluation and Organizational Development University of Louisville

Louisville, Kentucky

December, 2016 
Copyright 2016 by Paula F. Soder

All rights reserved 

WORKPLACE SPIRITUALITY AND EMPLOYEE WORK INTENTIONS:

EXAMINING THE RELATIONSHIP AND THE MEDIATING ROLE OF ETHICAL

\section{LEADERSHIP}

By

Paula F. Soder

B.S., Universidade de Santa Cruz do Sul, 2002

M.S., Marshall University, 2005

A Dissertation Approved on

December 5, 2016

by the following Dissertation Committee:

Dr. Brad Shuck, Chair (ELFH)

Dr. Meera Alagaraja, (ELFH)

Dr. Jason C. Immekus (ELFH)

Dr. Mark Leach (ECPY)

Dr. Carla Vidoni (HSS) 


\title{
DEDICATION
}

\author{
To Dennis Finnegan: \\ You are a constant source of love, friendship, patience, support, and encouragement. \\ My life is enriched because of you and Lilly.
}




\section{ACKNOWLEDGMENTS}

I would like to thank my advisor and dissertation chair, Dr. Brad Shuck, for believing in my ability to fulfill all the requirements of this degree. His guidance, encouragement and mentorship were critical to the completion of this dissertation. A special thanks to Dr. Jason Immekus for his support, feedback, and guidance through the study's methodology and writing process. Additionally, a very special thank you to Dr. Meera Alagaraja, Dr. Jason Immekus, Dr. Mark Leach, and Dr. Carla Vidoni who, in addition to my chair, agreed to serve on my committee and provide guidance during this process. I also would like to gratefully acknowledge Layne Gordon from the University of Louisville Writing Center for her careful reviews of the final chapters. To all of you, I am grateful for your time and patience, and hope that you will recognize the results of your advice in this final product. 


\section{ABSTRACT \\ WORKPLACE SPIRITUALITY AND EMPLOYEE WORK INTENTIONS: \\ EXAMINING THE RELATIONSHIP AND THE MEDIATING ROLE OF ETHICAL \\ LEADERSHIP \\ Paula F. Soder}

December 5, 2016

This dissertation examined the extent to which workplace spirituality was associated with work intentions, and whether ethical leadership served as a mediator of the relationship between workplace spirituality and work intentions. The study begins with an overview of the significant workplace spirituality literature, and a brief overview of work intentions and ethical leadership. A convenience sample of 405 U.S. based adults, employed full-time were surveyed. Using correlation and path analysis, results from the study showed a positive strong association between workplace spirituality and employee work intentions, and mediation via ethical leadership. The findings of the study provided support for both hypotheses.

Workplace spirituality received considerable attention in scholarship and practice over the past two decades (Duchon \& Plowman, 2005; Giacalone \& Jurkiewicz, 2010). As an emerging concept in contemporary literature (Ashmos \& Duchon, 2000; Giacalone \& Jurkiewicz, 2003; Stevens, 2008), workplace spirituality is broadly defined as an organization's recognition that employees have an inner life that nourishes and is nourished by meaningful work, and that takes place in the context of a community 
(Ashmos \& Duchon, 2000). Previous research reported that workplace spirituality was associated with positive benefits for both employees and organizations. This study extended the understanding of the contributions of workplace spirituality, a growing field of study, in the development of positive organizational cultures. Additionally, this study added to the existing body of research in which workplace spirituality is positioned as a construct that might positively affect employee work intentions, and consequently success of the organization and employee well-being. 
TABLE OF CONTENTS

PAGE

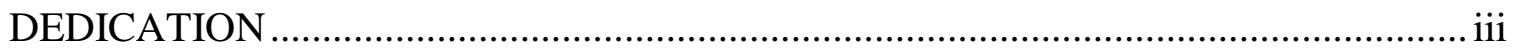

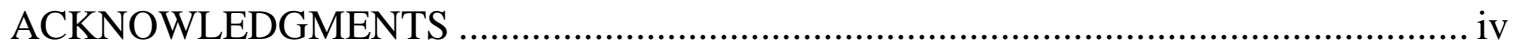

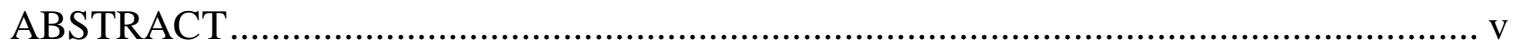

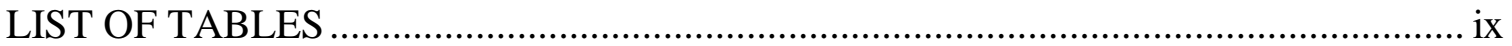

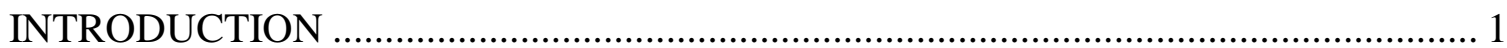

Statement of the Problem........................................................................................ 5

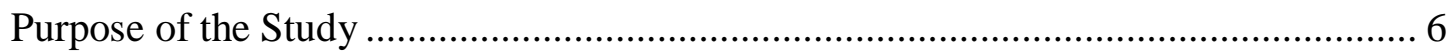

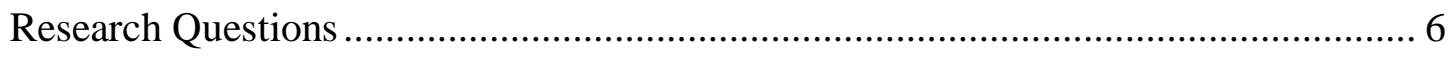

Significance of the Study ..................................................................................... 9

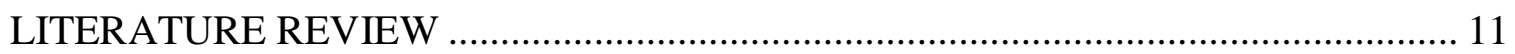

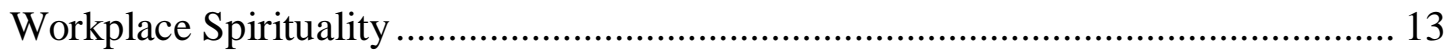

Definitions of Workplace Spirituality ...................................................................... 21

Dimensions of Workplace Spirituality ................................................................... 24

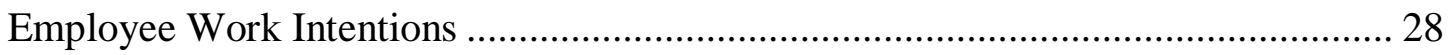

Ethical Leadership ........................................................................................... 34

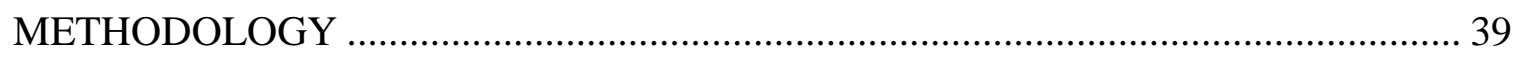

Research Questions and Hypotheses ......................................................................... 39

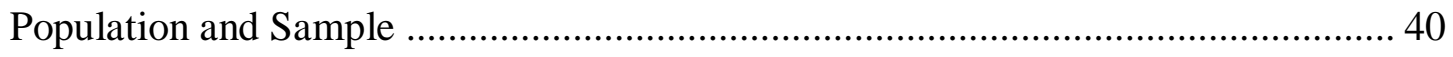

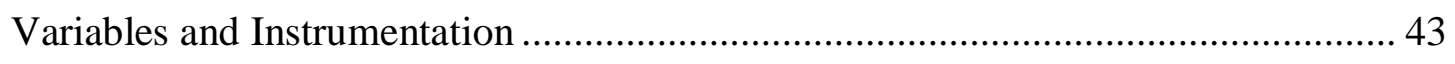

Controlling for Survey Errors …………………………....................................... 49 


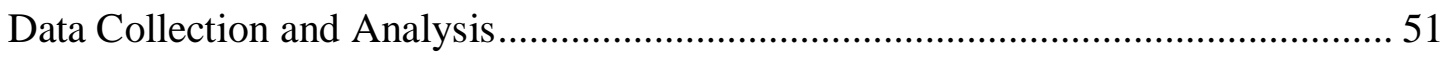

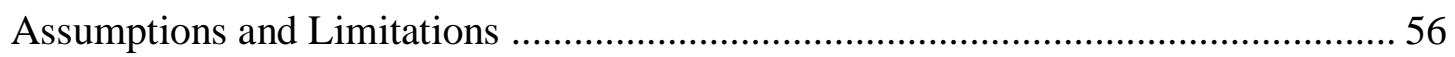

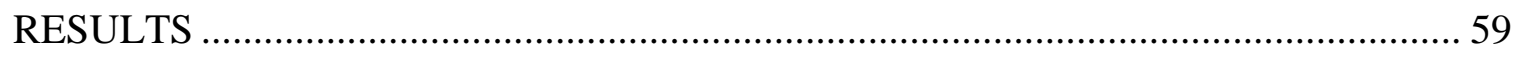

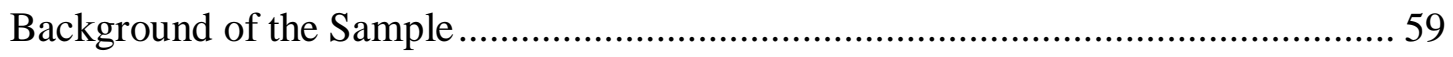

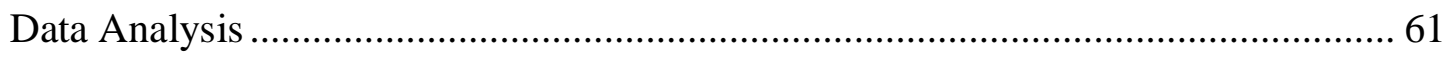

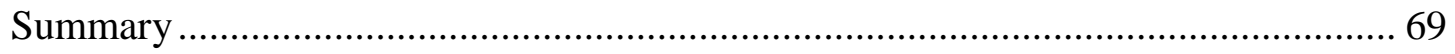

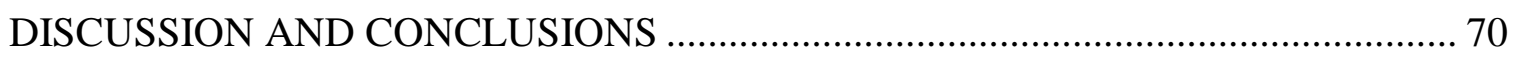

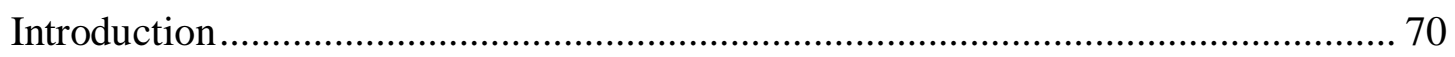

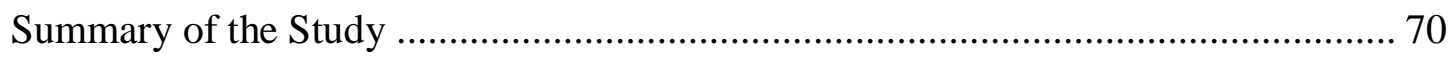

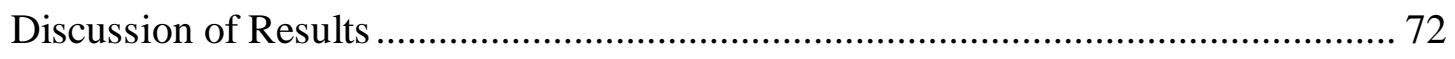

Implications for Theory, Research and Practice .............................................. 77

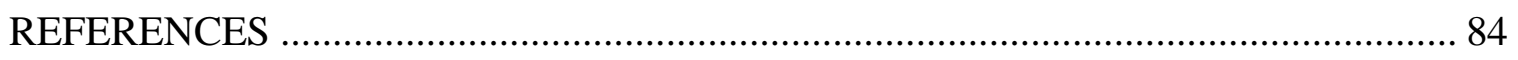

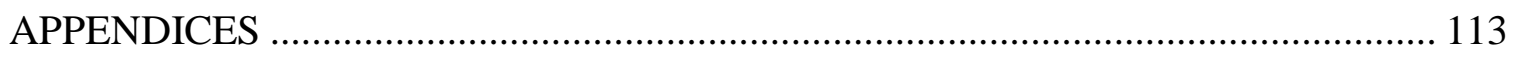

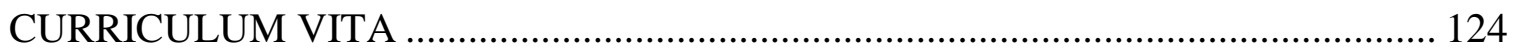




\section{LIST OF TABLES}

TABLE

PAGE

1. Representative Sample of Definitions for Workplace Spirituality ........................... 22

2. Participants Personal and Professional Attributes .................................................... 43

3. Selected Instruments and Reliability Statistics of Survey Items .............................. 48

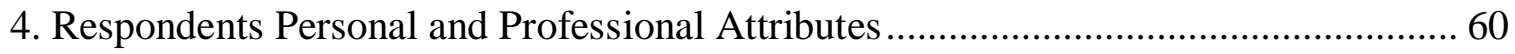

5. Descriptive Statistics and Correlations for Ethical Leadership, Workplace Spirituality

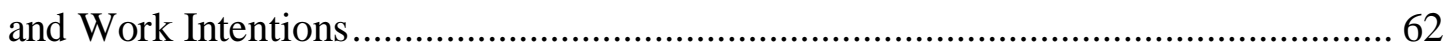

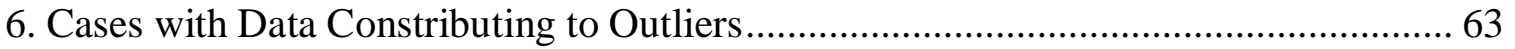

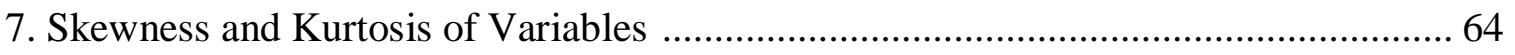

8. Subscale Level Correlations Between Workplace Spirituality and Work Intentions ... 66

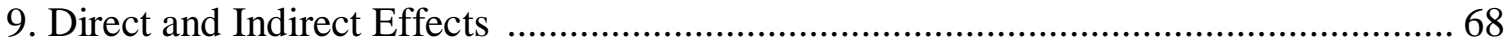




\section{CHAPTER I}

\section{INTRODUCTION}

Since the 1990s, scholars and practitioners have discussed workplace spirituality with increasing interest, ushering in a major paradigm shift in organizational sciences and management theory (Ashmos \& Duchon, 2000; Capra, 1996; Giacalone \& Eylon, 2000; Giacalone \& Jurkiewicz, 2003; Harman \& Hormann, 1990; Ray, 1993; Stevens, 2008). This study adopted Ashmos and Duchon's (2000) definition of workplace spirituality as the recognition that employees have an inner life that nourishes and is nourished by meaningful work, and that takes place in the context of their work community. The increased interest in the construct of workplace spirituality has been attributed to several emerging factors: (a) a desire by some organizations to nurture employees' dedication to their work and connection to the workplace (Fry \& Nisiewicz, 2013); (b) a shift from an industrial to an informational society that enabled organizations to decentralize and effectively reach stakeholders virtually anywhere in the world (Bowen, Ferris, \& Kolodinsky, 2010); and (c) a rapid pace of change, competitive business environments, and disruptive organizational events which contributed to job insecurity, feelings of detachment, and a search for meaning at work (Moxley, 2000; Noer, 2009).

From a human resource development (HRD) perspective, organizations are challenged to strike a balance between organizational performance and the essence of humanity that enables organizations to survive and even thrive (Callahan \& Ward 2001; Chalofsky 2000). The tendency to focus on organizational performance limits the 
understanding of employees as resources to be maximized and as means to organizational ends (Elliott \& Turnbull, 2004; Sambrook, 2012). In the context of this study, the tenets of workplace spirituality - meaningful work, alignment with organizational values, and sense of community - are valuable in themselves, rather than instruments to improve organizational outcomes.

HRD research and theories have yet to adequately capture the holistic and selfdirected nature of human beings in the context of the workplace. Within the HRD research context, individuals at work do not construe themselves into operational variables and categories, such as continuance commitment and turnover intention, but act, make decisions, and respond to demands and opportunities in the context of all aspects of their lives, including those related to work, family, community, and their private selves (Kuchinke, 2013). Scholars generally agreed in the research literature that workplace spirituality was driven by employees' desire to live integrated lives. Employees were no longer satisfied to park their spirituality or identity at the workplace door, any more than they were willing to deny or sublimate their ethnicity, race, gender, or sexual orientation (Miller, 2006; Mitroff \& Denton, 1999).

Despite the increased interest in workplace spirituality, as a scientific study, the topic has been limited by the lack of an accepted definition and inadequate measurement tools (Giacalone \& Jurkiewicz, 2010), scarce empirical and theoretical work (Giacalone \& Jurkiewicz, 2010; Lips-Wiersma, Dean, \& Fornaciari, 2009; Rego \& Cunha, 2008), and further complicated by a lack of understanding of variables that influence an individuals' experience at work (Miller \& Ewest, 2013). Consequently, several gaps exist within the literature. One such gap relates to untested theories given the nascent stage of 
the theory and instruments surrounding the construct. Workplace spirituality models have been criticized for lacking rigor and critical thinking (Gibbons, 2000), and only recently began to adequately assess variables germane to workplace spirituality (Miller \& Ewest, 2013).

Although previous research has begun to address certain aspects of workplace spirituality, additional research is necessary to further understand the holistic nature of human beings and the emergence of spirituality in the context of the workplace. To address a gap in the literature and evaluate workplace spirituality from the perspective of employees' reported experience and its effect on work intentions, this study examined the relationship between workplace spirituality and employees' intentions to engage in certain behaviors at work. As portrayed in the attitude-intention-behavior model, behavior is determined directly by an individual's intention to perform the behavior (Bagozzi, 1992). The concept of intentions has been reported in the psychological literature since the 1970s (Ajzen \& Fishbein, 1980; Fishbein \& Ajzen, 1975). Examples of models proposed to explain the relationship between intention and behavior include the theory of reasoned action (Fishbein \& Ajzen, 1975) and the theory of planned behavior (Ajzen, 1985, 1991). In each of these models, intentions play a key role in predicting of behavior.

Extending these theories to the workplace, work intentions are defined as a set of goal representations formed as a result of an appraisal process designed to meet an individual's needs and wants stemming from a sense of employee well-being (Zigarmi, Nimon, Houson, Witt, \& Diehl, 2012). Intentions have also been described as a guide to purposeful action, a mental representation of the behavior an employee chooses to 
manifest (Ajzen \& Fishbein, 1980; Bagozzi, 1992). Research findings indicate that behavioral intentions such as turnover intentions are better predictors of attrition than measures of overall job satisfaction, satisfaction with the work itself, or organizational commitment (Steel \& Ovalle, 1984). For example, the variables that bear a relationship to employee turnover are age, tenure, satisfaction with job content, overall job satisfaction, organizational commitment, and behavioral intentions to quit (Steel \& Ovalle, 1984). These variables are consistent with the theories stressing the importance of intent in predicting behavior (Ajzen \& Fish 1980). Fishbein and Ajzen (1975) asserted that the best single predictor of an individual's behavior is a measure of the intention to perform that behavior; they identified three major factors that influence the magnitude of the relationship between intention and behavior: (a) the degree to which intention and behavior correspond in their levels of specificity; (b) the stability of the expressed intention; and (c) the degree to which carrying out the intention is under the individual's volitional control.

A second gap in the workplace spirituality literature highlights the dearth of work around ethical considerations within the context of the workplace spirituality construct (Sheep, 2006). Existing literature proposed correlations between people, organizations, and spiritual phenomena in the workplace, yet was devoid on the topic of ethical considerations, and in particular, the role of ethical leadership in fostering workplace spirituality. The impact and influence of ethical leadership should be properly vetted (Miller \& Ewest, 2013).

Exploring the role of ethical leadership addresses the gap related to ethical work climates, as ethics in the workplace continues to receive attention, most notably in the 
leadership field. Ethical leadership is defined as the demonstration of normatively appropriate conduct through personal actions and interpersonal relationships, and the promotion of such conduct to followers through two-way communication, reinforcement, and decision-making (Brown, Treviño, \& Harrison, 2005). Ethics has been defined as the study of choices people make regarding right and wrong (Ruggiero, 2015). Considering the role of leaders within organizations, ethical leaders are likely sources of guidance for followers because of their position of authority and credibility as role models of behavior (Brown et al., 2005).

Scholars have suggested that a culture of workplace spirituality was positively related to ethical mindsets, as organizational members responded positively to values such as integrity, honesty, compassion, and trustfulness (Issa \& Pick, 2010).

Notwithstanding, the presence of workplace spirituality could improve an understanding of workplace ethics, although, despite similarities, the workplace spirituality and ethics movement developed largely independently yet both focus on personal integrity, moral growth, and are concerned with making the workplace and business environment more humane, guided by visionary leaders concerned with the physical environment and a sustainable future for all (Cavanaugh, 1999).

\section{Statement of the Problem}

Workplace spirituality is subject worthy of research because of its strong relevance to the well-being of individuals, organizations, and societies (Sheep, 2006). Further scientific inquiry may contribute new developments to organizational science (Giacalone \& Jurkiewicz, 2003). As few in-depth studies have been conducted on this topic, theory conceptualization appears to be stronger than empirical evidence (de Klerk, 
2005); consequently, empirical work has been the exception and not the rule in the scholarship on workplace spirituality (Duchon \& Plowman, 2005). To address this limitation, empirical research in workplace spirituality must receive greater attention, as doing so could provide additional data regarding the numerous benefits for employees and organizations that have been linked to workplace spirituality.

Moreover, ethical leadership has been linked to higher levels of productivity (Den Hartog \& Belschak 2012; Piccolo, Greenbaum, Den Hartog, \& Folger, 2010). As such, if this work indicates that ethical leadership mediates the relationship between workplace spirituality and work intentions, the ultimate advantage of fostering workplace spirituality and ethical leadership comes in the form of employees with positive work intentions, and by in-direct extension, increased productivity, satisfaction and retention. In light of the strategic role workplace spirituality could play in impacting employee well-being and performance, understanding the relationship between workplace spirituality, work intentions, and ethical leadership may provide important leverage for HRD and stimulate future research and theory building, a significant potential outcome of this research.

\section{Purpose of the Study}

The purpose of this study was to examine the relationship among workplace spirituality and work intentions. Specifically, this study assessed the extent to which workplace spirituality was associated with work intentions, and whether ethical leadership mediated the relationship between workplace spirituality and work intentions.

\section{Research Questions}

This study was guided by two main research questions: 
RQ 1: What is the relationship between employees' workplace spirituality and work intentions?

RQ 2: Does ethical leadership mediate the relationship between employees' workplace spirituality and work intentions?

\section{Definition of Variables and Terms}

Terms used throughout this study are defined as follows:

Workplace spirituality is the recognition that employees have an inner life that nourishes and is nourished by meaningful work taking place in the context of community (Ashmos \& Duchon, 2000). Workplace spirituality involves the individual's effort to find his or her ultimate purpose in life, to develop a strong connection to coworkers and other people associated with work, and to have alignment between the individual's core beliefs and the values of his or her organization (Mitroff \& Denton, 1999). Workplace spirituality will serve as an independent variable with three levels: sense of community, alignment with organizational values, and meaningful work.

Alignment with organizational values is defined as employees' desire to work in an organization whose goal is to be more than a good corporate citizen - an organization that seeks to have a high sense of ethics or integrity and make a larger contribution than the typical company to the welfare of employees, customers and society (Milliman, Czaplewski, \& Ferguson, 2003).

Meaningful work is defined as the degree to which the individual experiences the job as generally meaningful, valuable, and worthwhile (Hackman \& Oldham, 1976). 
Sense of community is defined as the essence of community involving a deeper sense of connection among people, including support, freedom of expression, and genuine caring (Milliman et al., 2003).

Work intentions are defined as a set of goal representations formed as a result of an appraisal process that is designed to meet an individual's needs and wants stemming from a sense of employee well-being (Zigarmi et al., 2012). This study adopted the short form of the Work Intention Inventory (Nimon \& Zigarmi, 2015) to assess a set of five work intentions resulting from employees' state of well-being (or lack thereof). This variable served as a dependent variable and consisted of following five dimensions: intent to endorse, intent to engage organizational citizenship behaviors (OCB's), intent to exert discretionary effort, intent to perform, and intent to stay.

Intent to endorse is defined as the extent an employee intends to endorse the organization to others as a good place to work and as a quality supplier of goods and services (Zigarmi et al., 2012).

Intent to engage organizational citizenship behaviors (OCBs) is defined as the extent an individual intends to behave in ways that are respectful, considerate, and sensitive to others and which support the welfare and effectiveness of the entire organization (Zigarmi et al., 2012).

Intent to exert discretionary effort is defined as the intent of an employee to expend efforts on behalf of the organization, above and beyond the agreed-upon requirements (Zigarmi et al., 2012). 
Intent to perform is defined as the extent employees intend to do their jobs at a higher than average level, thereby effectively helping the organization succeed (Zigarmi et al., 2012).

Intent to stay is defined as the extent an employee intends to remain within an organization (Zigarmi et al., 2012).

Ethical leadership is defined as the demonstration of normatively appropriate conduct through personal actions and interpersonal relationships and the promotion of such conduct to followers through two-way communication, reinforcement and decisionmaking (Brown et al., 2005). Brown et al. (2005) addressed ethical leadership from a social learning perspective and suggested followers will eventually behave similarly to their leader through imitation and observational learning.

\section{Significance of the Study}

Workplace spirituality is a rapidly growing field of study. Defining the contributions workplace spirituality makes to employee's experience of meaningful work, sense of community, and alignment with organizational values, and how these experiences might affect work intentions or are mediated by ethical leadership, are paramount to understanding the 21 st-century workforce. The construct of workplace spirituality and its influence on work intentions has relevance to the field of organizational development and HRD. There is a need to test this construct empirically because, as has been noted in previous research, empirical work on the subject is scarce (Giacalone \& Jurkiewicz, 2003; Lips-Wiersma et al., 2009; Rego \& Cunha, 2008). Hence, this study is significant for the following reasons. First, this study will add to the existing body of research in which workplace spirituality is positioned as a construct that 
might positively affect employee work intentions, and consequently success of the organization and employee well-being. Second, this study will investigate whether ethical leadership serves as a mediating variable for work intentions resulting from workplace spirituality. This study posits that workplace spirituality and ethical leadership coexist in an organizational setting. Collectively, these variables could strengthen work intentions and lead to outcomes benefiting both employees and the organization. 


\section{CHAPTER II}

\section{LITERATURE REVIEW}

This study set forth to examine the relationship between workplace spirituality and work intentions. Specifically, this study assessed the extent to which workplace spirituality was associated with work intentions, and whether ethical leadership mediated the relationship between workplace spirituality and work intentions. This chapter provides a review of the relevant literature focused on workplace spirituality, and reports on the foundational background for the variables of workplace spirituality, work intentions, and ethical leadership.

The evolution of human society is reflected in the evolution of the workforce; for example, the agrarian society progressed economically into an industrial society and, eventually, into the information era. Appropriately, this evolution is also reflected in organizational theories; therefore, the interest in workplace spirituality is a natural progression of management theory since the early 1900s. The early theories of Taylor (1911), for example, focused on mechanical efficiency and made use of the science of time and motion, seeing workers as mere ends, a sharp contrast with newer theories, including workplace spirituality, which emphasizes the whole person.

The underlying premise of Taylor's (1911) theory was the concept of economic man: that people were primarily motivated by money. Taylor's theory was concerned with maximizing the use of physical energy, and human beings were considered extensions of the machines they operated. In the decades that followed, the Hawthorne 
studies in the late 1920 s raised questions concerning the motivating influences for untapping potential, the qualities of effective leadership and supervision, worker participation and involvement in company decision-making, job satisfaction, resistance to change, and group norms (Sonnenfeld, 1985). The Hawthorne studies revealed the relational aspects of work and how those aspects shaped productivity and the meaning that people made of it (Mayo, 1949). For Mayo, the study unveiled that physical energy affected work output as well as emotional energy.

Workplace spirituality, an emerging field of study, is faced with many of the issues associated with development of any new theory. For example, matters of definition continue to be a subject of concern (Geigle, 2012). Empirical studies demonstrated a positive effect of workplace spirituality on job commitment, satisfaction, and performance (Fry \& Nisiewicz, 2013; Jurkiewicz \& Giacalone, 2004; Karakas, 2010; Krishnakumar \& Neck, 2002). One in-depth study found that work unit performance in five hospitals was associated with work unit spirituality, and that leaders have an impact on work unit spirituality (Duchon \& Plowman, 2005). Furthermore, research in the field of workplace spirituality demonstrated results in altruism and conscientiousness, selfcareer management, reduced inter-role conflict, reduced frustration, organization based self-esteem, involvement, retention, and ethical behavior (Geigle, 2012).

To contribute to the research in this developing area, this study explored the relationship among workplace spirituality and employee work intentions. Specifically, this study examined the extent to which workplace spirituality affected work intentions, and whether ethical leadership mediated the relationship between workplace spirituality and work intentions. The first section of this chapter reviews salient literature on 
workplace spirituality and is organized in three subsections. The subsections review each of the three dimensions of workplace spirituality of interest to this study: (a) sense of community, (b) alignment with organizational values, and (c) meaningful work. The second section of the chapter provides a review of the relevant literature on work intentions and its connection to workplace spirituality. The third section focuses on ethical leadership, particularly the relevant aspects that are independent of other types of leader behavior. The concluding summary describes the theoretical connection among the variables and the potential benefits they could offer to organizations.

\section{Workplace Spirituality}

Empirical work on workplace spirituality emerged in the 1990s. Widely regarded as the first large-scale empirical study on the phenomenon, Mitroff and Denton (1999) reported a yearning for more spiritual openness in workplaces among the executives they interviewed, and found that most organizations suffer from spiritual impoverishment. Of primary interest to their study were personal meanings people attached to the concepts of religion and spirituality. As such, their study focused on the "emergent" definitions of religion and spirituality of managers and executives. They refrained from defining religion and spirituality a priori, but instead let it emerge from the respondents. Participants' responses indicated religion was viewed primarily as a dogmatic and institutional phenomenon, whereas spirituality was viewed as an individual phenomenon (Mitroff \& Denton, 1999).

Mitroff and Denton (1999) offered five organizational models of spirituality in the workplace. These models included: (a) the religion-based organization, (b) the evolutionary organization, (c) the recovering organization, (d) the socially responsible 
organization, and (e) the values-based organization. They evaluated these models against 10 dimensions and concluded a combination of the five models — a hybrid model—was more fitting and least likely to incur intense counteraction by stakeholders. This inherently conservative strategy was the best alternative at the time, and could be adopted to promote spirituality in organizations to allow for implementation and practice of workplace spirituality without inducing hostility, conflict, controversy, and division over fundamental beliefs and values. Mitroff and Denton (1999) separated spirituality from religion, advocating for spirituality in the workplace and arguing against religious expression in a workplace context. They supported the notion that workplace spirituality was about finding a purpose in life, creating a strong connection with coworkers, and having a match between an individual's core values and the values of the organization. Additionally, they noted that organizations with a stronger sense of spirituality enabled employees to exercise stronger values and ethics in the workplace, empowering creativity and flexibility. Through their study, Mitroff and Denton concluded that workers who could express their spirituality through work found work more satisfying and meaningful, and therefore, took their job performance to a higher level.

Ashmos and Duchon (2000) advanced Mitroff and Denton's (1999) work by developing the Spirituality at Work scale. The instrument measured three dimensions germane to spirituality in the workplace: inner life, meaningful work, and a sense of connection and community. These three dimensions took into account employees attitudes and perceptions about themselves and their work environment, their work unit, and their work organization as a whole. The organizational aspect of the instrument was concerned with how well an individual identified with the mission, values, and goals of 
the organization. The primary purpose of this instrument was to facilitate understanding of how spirituality could contribute to more productive work organizations. Ashmos and Duchon tested the construct of spirituality at work by identifying the dimensions of that construct and introduced the "spirituality movement" term, whereby they noted that organizations, which have long been viewed as rational systems, were considering making room for a spiritual dimension with less to do with rules and order, and more to do with meaning, purpose, and a sense of community.

As workplace spirituality gained strength and interest, the Academy of Management created a special interest group for its members in 2000. The Management, Spirituality, and Religion interest group focused on interdisciplinary, theoretical, applied research and pedagogy related to the relevance and relationship of spirituality and religion in management and organizational life. As of late 2015, the 616-member group was primarily focused on furthering members' research agenda (Academy of Management, 2015).

In the following years, a study by Milliman et al. (2003) examined three dimensions of workplace spirituality, meaningful work, sense of community, and alignment with organizational values, and their relationship with employee work attitudes. Using a sample of MBA students, Milliman and colleagues found a positive relationship between workplace spirituality and organization commitment, intention to quit, intrinsic work satisfaction, job involvement, and organization-based self-esteem. This study was valuable as it provided additional validity support for Ashmos and Duchon's (2000) measurement instrument. Additionally, this study suggested that future research should explore organizational variables such as organizational citizenship, which 
were not part of formal job duties but rather discretionary behavior that promoted organizational effectiveness.

In Religion and the Workplace, Hicks (2003) analyzed emerging matters regarding spirituality and religion in the workplace literature. Hicks agreed with Mitroff and Denton (1999): employees should not be asked to park their souls at the door. Hicks argued that efforts to decouple spirituality and religion in the workplace were naive and ineffective, and proposed an alternative way to integrate spirituality, religion, and work. He coined the notion of respectful pluralism, and advocated that organizations should allow employees to bring their own spirituality and religion to work. With this approach, employees could maintain those values that were already instilled in them when they entered the work environment, and in turn, encourage an environment where employees felt free to exercise their own beliefs and values.

Giacalone and Jurkiewicz (2003a) edited the Handbook of Workplace Spirituality and Organizational Performance, the largest collection of essays on the subject assembled to that time, arguing for the necessity of linking workplace spirituality to organizational performance, integrating psychology, spirituality, and organizational science. Like Mitroff and Denton (1999), Giacalone and Jurkiewicz suggested that integrating spirituality and work would improve organizational performance. Seven years later, a second edition of the handbook was published (Giacalone \& Jurkiewicz, 2010). In the foreword to the second edition, Delbecq (2010) praised the revised handbook for increased sophistication in organizational studies. However, the second edition also reinforced the fundamental need for a scientific and empirical approach to workplace spirituality. While conceptual development remained important, the study of workplace 
spirituality also needed to demonstrate outcomes in order for it to be seen as a legitimate discipline for both scholars and practitioners. Without evidence, this emerging paradigm could be at risk of being marginalized as a theoretical and unrealistic pursuit.

Duchon and Plowman (2005) explored the relationship between work unit spirituality and performance in a study of six work units in a large hospital system. According to their study, the construct of organizational spirituality rested upon the notion that organizational members had spiritual needs. Duchon and Plowman argued that the three components in the definition of spirituality proposed by Ashmos and Duchon (2000) — inner life, meaningful work, and a sense of community — have theoretical foundations in the management literature and were what consequentially shaped a spirit-friendly climate and organization. Using nonparametric procedures, their findings suggested that there was a positive relationship between work unit spirituality and work unit performance.

Pointing to the increase in interest in the subject, Oswick (2009) compared the two 10-year periods ending in 1998 and 2008 and found the number of books on workplace spirituality increased from 17 to 55, and the number of journal articles increased from 40 to 192 . Karakas (2010) reviewed the literature and found 70 definitions of spirituality at work. Karakas (2010) integrated three different perspectives on how spirituality enabled or lead to organizational performance. First, the human resources perspective enhanced employee well-being and quality of life by increasing employee morale, commitment, and productivity, and by reducing stress, burnout, and workaholism. Second, the philosophical perspective provided employees a sense of purpose and meaning at work. Third, the interpersonal perspective provided employees a 
sense of interconnectedness and community, increasing employee attachment, loyalty, and feeling of belonging to the organization. While workplace spirituality has the capacity to increase organizational performance, the positive effects on employee wellbeing and quality of life are fundamental reasons for its advocacy.

Kolodinsky, Giacalone, and Jurkiewicz (2008) offered three distinct conceptual understandings of workplace spirituality. First, at the individual level, workplace spirituality reflected a simple application of personal spirituality — the totality of personal spiritual values an individual brings to the workplace and how such values influence both ethically related and ethically unrelated worker interactions and outcomes. Second, at the macro level, the spiritual climate or culture of an organization reflected its organizational spirituality — an individual's perception of the spiritual values present in an organizational setting. Third, understanding the impact of spirituality on work was not merely a function of a micro or macro value structure alone, but of the interactive impact of individual and organizational spirituality in the work setting (Kolodinsky, Giacalone, \& Jurkiewicz, 2008). The results of their study were somewhat mixed; the authors discovered that the organizational level of spirituality more broadly and significantly impacted job involvement, organizational identification, rewards satisfaction, and negative organizational frustration. The authors noted that their findings suggested that workers desired workplaces perceived as exuding spiritual values, even if the workers themselves were not personally spiritual. Likewise, their study suggested that personal spirituality is positively related to intrinsic, extrinsic, and total rewards satisfaction. In summary, Kolodinsky et al.'s findings supported the notion that perceptions of organizational spirituality affect attitudinal and attachment-related worker consequences. From these 
exploratory results, it appeared that organizations fostering cultures characterized by spiritual attributes realized important worker benefits.

Further, Karakas (2010) reviewed spirituality at work literature and explored how spirituality improved employees' performance and organizational effectiveness. Karakas established a relationship between spirituality and organizational performance. He introduced three different perspectives on how spirituality benefited employees and supported organizational performance based on the existing literature: (a) spirituality enhanced employees' well-being and quality of life, (b) spirituality provided employees a sense of purpose and meaning at work, and (c) spirituality provided employees a sense of interconnectedness and community. Karakas concluded by introducing potential benefits and caveats of bringing spirituality into the workplace, warning to proceed carefully in implementing spirituality programs at work, as it could be counterproductive, alienating, and disastrous for some people. Additionally, the study provided recommendations and suggestions for practitioners to consider when incorporating spirituality, including a) accommodation of spiritual requests, b) respect for diversity, and c) openness and freedom of expression.

As workplace spirituality became more firmly established as a field of study, the work of scholars reflected that journey. Contributing to the theoretical development of workplace spirituality, Dehler and Welsh (2010) offered twofold key concerns: "recognizing that people bring their whole selves to their jobs, and that work needs to be designed to be challenging, in order to energize, or more appropriately inspirit, people in relating to their tasks" (p. 69). In their study on the experience of work, Dehler and Welsh suggested a fundamental employer or managerial philosophy that seeks to align 
workers' values with the purpose of the organization beyond its bottom line; they warned, however, that if spirituality was invoked only because it enhanced the bottom line, the approach would fail because talent and knowledge would walk out the door in search of meaning. On the other hand, if spirituality was invoked because it is the right thing to do in creating a thriving workplace where individual and organizational outcomes were integrated, then its future was promising.

Although workplace spirituality is associated with much positive regard, there also is the potential for misuse, a negative aspect that could be detrimental instead of beneficial. Critics of workplace spirituality did not claim that it is inappropriate per se, but warned about the ways it could be misused or manipulated, particularly for organizational control (Bell \& Taylor, 2004; Boje, 2008) and instrumental gain (Benefiel, 2003; Lips-Wiersma \& Nilakant, 2008; Steingard, 2005). Gull and Doh (2004) warned that implementing spirituality in the workplace with the sole purpose of realizing greater competitive advantage, higher and more efficient levels of productivity and greater profit might translate to benefits in the short term, but it would be dishonoring to humankind and counterproductive to the unfolding of spirit. Additionally, the nonmaterialistic essence of spirituality does not focus on organizational material gains. Rather, the question for workplace spirituality focuses on how organizations can better reflect the whole human being (Briskin, 1998).

Work communities are becoming a venue for individuals to discover meaning and purpose, and make contributions. Fairholm (2011) suggested that workers were looking to the workplace as a source of spiritual support; he explained that 21st-century workers are seeking emotional fulfillment on the job, and contemporary literature was confirming 
a felt need for work communities, leadership, and work systems that celebrate the whole individual. This idea also resonates with the words of Roethlisberger (1941), who stated that "a man whose job is without social function is like a man without a country; the activity to which he has to give the major portion of his life is robbed of all human meaning and significance” (p. 170).

\section{Definitions of Workplace Spirituality}

A fundamental step in the scientific study of any phenomenon is a careful definition of terms, which perhaps has been one of the greatest challenges to researchers of workplace spirituality. Numerous scholars have commented at length on the lack of definitional clarity concerning workplace spirituality (Cavanagh, 1999; Gotsis \& Kortezi, 2008; Marques, Dhiman, \& King, 2007; Rego \& Cunha, 2008; Tischler, Biberman, \& Altman, 2007; Van der Walt \& de Klerk, 2014). An important advancement in searching

for a definitional construct of workplace spirituality was the separation of individual and organizational spirituality (Kinjerski \& Skrypnek, 2004).

Defining spirituality itself is a challenge. Any single definition of this complex construct is unlikely to satisfy everyone. Psychological definitions of spirituality are diverse, ranging from the best of that which is human, to a quest for existential meaning, to the transcendent human dimension (Zinnbauer \& Pargament, 2005). In this dissertation, spirituality is defined as "a search for the sacred" (Pargament, 1999, p. 12). Spirituality can also be defined quite broadly, with the term encompassing a search for meaning, for unity, connectedness, transcendence, for the highest of human potential (Emmons, 1999). The Dalai Lama identified spirituality as concerned with qualities of the human spirit, such as love and compassion, patience, tolerance, forgiveness, 
contentment, a sense of responsibility and harmony (Gyatso, 1999). Other positive psychological concepts suggest spirituality to be related to individual motivation to find sacred meaning and purpose in their existence (Tepper, 2010). The concepts of meaning, connectedness and transcendence are central to the most cited definitions of spirituality the context of the workplace. Traditionally, in the field of psychology, no distinction was made between the constructs of spirituality and religion (Wulff, 1998); however, writers have begun to contrast the two, suggesting that religion is institutional, dogmatic and restrictive, while spirituality is personal, subjective and life enhancing (Elkins, 1995; Emblen, 1992).

Although several definitions of workplace spirituality have been promoted, no widely accepted definition exists in the field, a key weakness and limitation to the emergence of a definitive scientific study (Giacalone \& Jurkiewicz, 2010). The interchangeable use of the terms workplace spirituality, spirituality at work, and organizational spirituality to articulate the relationship between the workplace and spirituality (Kinjerski \& Skrypnek, 2004) further complicate defining the construct. Some of the definitions of workplace spirituality used in scholarly works relevant to this study are shown in Table 1.

Table 1

Representative Sample of Definitions for Workplace Spirituality

\begin{tabular}{ll}
\hline \multicolumn{1}{c}{ Definition } & \multicolumn{1}{c}{ Source } \\
\hline $\begin{array}{l}\text { Spirituality in the workplace is about seeing work as a spiritual } \\
\text { path, as an opportunity to grow personally and to contribute to } \\
\text { society in a meaningful way. }\end{array}$ & Neal, 1997. \\
$\begin{array}{l}\text { A recognition of employees inner life that nourishes } \\
\text { and is nourished by meaningful work, and takes place in the } \\
\text { context of community. }\end{array}$ & Ashmos and \\
\end{tabular}




\begin{tabular}{|c|c|}
\hline Definition & Source \\
\hline $\begin{array}{l}\text { A journey toward integration of work and spirituality which } \\
\text { provides direction, wholeness, and connectedness at work. }\end{array}$ & Gibbons, 2000. \\
\hline $\begin{array}{l}\text { Positively sharing, valuing, caring, respecting, acknowledging, } \\
\text { and connecting the talents and energies of employees in } \\
\text { meaningful goal-directed behavior that enables them to belong, } \\
\text { be creative, be personally fulfilled, and take ownership in their } \\
\text { combined destiny. }\end{array}$ & $\begin{array}{l}\text { Adams and } \\
\text { Csiernik, } 2002 .\end{array}$ \\
\hline $\begin{array}{l}\text { Involves the desire to do purposeful work that serves others, to } \\
\text { be part of a principled community, a yearning for connectedness } \\
\text { and wholeness that can only be manifested when one is allowed } \\
\text { to integrate one's inner life with one's professional role in the } \\
\text { service of the greater good. }\end{array}$ & $\begin{array}{l}\text { Ashar and Lane- } \\
\text { Maher, } 2004 .\end{array}$ \\
\hline $\begin{array}{l}\text { An experience of interconnectedness initiated by authenticity, } \\
\text { reciprocity, and personal goodwill; a deep sense of meaning that } \\
\text { is inherent in the organization's work, resulting in greater } \\
\text { motivation and organizational excellence. }\end{array}$ & $\begin{array}{l}\text { Marques et al., } \\
2007 .\end{array}$ \\
\hline $\begin{array}{l}\text { Aspects of the workplace that promote feelings of satisfaction } \\
\text { through transcendence; a work process that facilitates } \\
\text { employees' sense of being connected to a nonphysical force } \\
\text { beyond themselves, that provides feelings of completeness and } \\
\text { joy. }\end{array}$ & $\begin{array}{l}\text { Giacalone and } \\
\text { Jurkiewicz, } 2010 .\end{array}$ \\
\hline
\end{tabular}

Empirical research studies suggested numerous benefits of workplace spirituality, ranging from increased creativity, honesty, trust, personal fulfillment and commitment, which ultimately lead to increased organizational performance (Krishnakumar \& Neck, 2002). Moreover, organizational spirituality promotes a sense of community within the organization (Ashmos \& Duchon, 2000), and organizations fostering sense of community also realize the benefits of employee retention and devotion to the organizational vision (Duchon \& Plowman, 2005; Karakas, 2010). Additionally, organizations with a spiritual culture and climate promoted positive customer experiences (Pandey, Gupta, \& Arora, 2009), and exhibited a higher set of ethical values (Pawar, 2009). Finally, studies have 
revealed that workplace spirituality had positive effects on employee job performance and attitudes (Jurkiewicz \& Giacalone, 2004).

\section{Dimensions of Workplace Spirituality}

The proposed study examined three dimensions of workplace spirituality. The first dimension of sense of community relates to how people see themselves as connected to each other in some type of relationship between one's inner self and the inner self of other people. The second dimension of meaningful work represents the degree to which people experience a deep sense of meaning and purpose at work. The third dimension of alignment with organizational values represents the experience of a strong sense of alignment between personal values and the organization's mission and purpose. These dimensions were selected for three main reasons: first, they were hypothesized to have an important relationship with the study objective of employee work intentions. Second, they have been tested and reported as relevant in previous studies (Ashmos \& Duchon, 2000; Duchon \& Plowman, 2005; Jurkiewicz \& Giacalone, 2004; Milliman et al., 2003; Rego \& Cunha, 2008; Rego, Cunha, \& Souto, 2007). Third, these dimensions portray aspects of workplace spirituality expressed at individual and organizational levels, potentially able to contribute to an understanding of this emerging concept in the workplace. The next three subsections review the dimensions of workplace spirituality adopted in this study.

\section{Sense of Community}

Sense of community is a dimension of workplace spirituality that occurs at the group level of human behavior, and is expressed via interactions between coworkers (Milliman et al., 2003). Sense of community involves a deep connection to or relationship 
with others (Ashmos \& Duchon, 2000). This level of spirituality involves the mental, emotional, and spiritual connections among employees in teams or groups in organizations (Neal \& Bennett, 2000). The essence of community is a deeper sense of connection among people, including support, freedom of expression, and genuine caring (Milliman et al., 2003). Community can be described as a partnership of free people committed to the care and nurturing of one another's mind, body, heart, and soul through participatory means (Naylor, Willimon, \& Österberg, 1996). Individuals in workplaces experience sense of community in the presence of shared vision, common values, boundaries, empowerment, shared responsibility, growth and development, tension reduction, education, feedback, and friendship (Naylor et al, 1996). People value workplaces where they feel part of a community (Miller, 1998; Pfeffer \& Veiga, 1999), and employees find strong connectedness in workplaces where they experience shared values and a shared sense of purpose (Chappell, 1993).

An authentic sense of community is autonomous and collaborative rather than imposed, driven by social rather than extrinsic motivation; employees feel encouraged to be authentic and allow for personal connections to form rather than assume impersonal connections via their roles (Garrett, Spreitzer, \& Bacevice, 2014). In practice, Southwest Airlines exemplifies an organizational culture with deliberate effort to evoke a sense of community. Employees feel that they are part of a family that takes care of each other as well as their customers; although a strong emphasis is placed on customers, employees come first (Frieberg \& Freiberg, 1996; Levering \& Moskowitz, 1993). While Southwest Airlines values community and having fun, it also has a strong work ethic with the expectation of hard work and flexibility to control staffing requirements below their 
competitors (Levering \& Moskowitz, 1993). For Southwest employees, working hard and having fun are not at odds with each other, but related to its business strategy of offering low-cost air travel to customers who ordinarily couldn't afford to fly; the company highlights emotional expression and humor, offering an extremely personable and funoriented brand of service quality (Milliman, Ferguson, Trickett, \& Condemi, 1999).

\section{Meaningful Work}

Meaningful work is a dimension of workplace spirituality that occurs at the individual level, and embodies how employees interact with their day-to-day work (Milliman et al., 2003). As such, this dimension involves the assumption that people have inner motivations, truths, and desires to be involved in activities that give greater meaning to their lives and the lives of others, and a desire to work on something seen as important, energizing, and fulfilling (Ashmos \& Duchon, 2000). Morse and Weiss's (1955) seminal study explored the meaning of work and found that most respondents viewed their jobs beyond the economic utility of earning a living.

Steger, Dik, and Duffy (2012) defined meaningful work as "work that is both significant and positive in valence (meaningfulness)" (p. 323). As such, employees who believe their work is meaningful report greater well-being (Steger, Dik, \& Duffy, 2012); perceive their work as more central and important (Arnold, Turner, Barling, Kelloway, \& McKee, 2007); place higher value on work (Harpaz \& Fu, 2002); and report greater job satisfaction (Nord, Brief, Atieh, \& Doherty, 1990). Empirical research has shown work is often an important source of meaning in life as a whole (Kamdron, 2005). Steger et al. (2012) suggested meaningful work might help people deepen their understanding of themselves and the world around them, facilitating their personal growth; thus, this facet 
helps capture the broader life context of people's work. Organizational scholars have long recognized people derive meaning from their work, and this meaning plays an important role in workers' attitudes and behaviors (Duchon \& Plowman, 2005).

\section{Alignment with Organizational Values}

Alignment with organizational values is understood as a match between an employee's personal beliefs, values, and ideas and the mission and purpose of the organization (Milliman et al., 2003). As such, alignment with organizational values involves the concept that employees desire to work in an organization whose goal is to not just be a good corporate citizen, but also an organization with a high sense of ethics or integrity and that make a larger contribution than the typical company to the welfare of employees, customers, and society (Milliman et al., 2003). Alignment also means individuals believe managers and employees in their organization have appropriate values, a strong conscience, and are concerned about the welfare of their employees and community (Ashmos \& Duchon, 2000).

Alignment between individual and organizational values creates a natural connection between people throughout the organization in such a way that relationships between one person and another, between the present and the future, between customer and product, a team and its goals, a leader and a vision - are claimed to be strengthened by aligned values (Branson, 2008). Where the organization cultivates alignment between organizational and individual values it induces more positive employee attitudes such as organizational commitment and job satisfaction (O'Reilly, Chatman, \& Caldwell, 1991). Alagaraja and Shuck (2015) defined alignment as "an adaptive, dynamic resource capability achieved by developing a shared understanding of interdependent systems, 
practices, and routines of the organization" (p. 21). Their study noted that alignment offered a contextual explanation of factors that impact employee performance or behaviors in an organization, and suggested that alignment provided meaning, a sense of purpose, and understanding of the organization such that the employee was able to interpret, search for, make meaning, and identify with the organization's current and future course of actions.

\section{Employee Work Intentions}

The theory of intentions has been advanced in the psychological and sociological literature in the past four decades. Models such as the theory of reasoned action (Fishbein \& Ajzen, 1975) and the theory of planned behavior (Ajzen, 1985) explain the relationship between intentions and behavior. Questions about how to increase performance or reduce turnover focus on a behavioral criterion, with the focus of predicting an outcome. As most workplace employee behaviors are under volitional control, they are predictable from intentions, and with the appropriate measure, intention becomes the most accurate predictor of behavior (Ajzen \& Fishbein, 1980). Employee performance is of fundamental concern for organizations; investigators measured job satisfaction, organizational climate, and commitment to the organization, and these studies show that job satisfaction is proposed to be the primary determinant of job performance and most other job-related behaviors (Fishbein \& Ajzen, 2010).

The theory of reasoned action specified intention as a central determinant of behavior (Ajzen, Albarracin, \& Hornik, 2007). Building on the intention-behavior model with the goal of improving the understanding human behavior in the workplace, this study examined whether workplace spirituality was a determinant of work intentions. The 
construct of work intentions developed by Zigarmi et al., (2012) is defined as a set of goal representations formed as a result of an appraisal process that is designed to meet an individual's needs and wants stemming from a sense of employee well-being. Recent research established significant correlations between work intentions and positive jobrelated affect, such that employees reporting more favorable affective states were more likely to intend to be organizational citizens, to perform, to try hard, to remain with their organization, and to endorse their company (Roberts \& Zigarmi, 2014).

Employing this line of thought to the issue of workplace spirituality, it is sensible to believe that employees' assessment of their experience in the workplace in terms of meaningful work, sense of community and alignment with organizational values would influence their intentions (to perform, to stay with and endorse their organization, to engage in organizational citizenship behaviors, and to use discretionary effort) — and that this relationship was partially mediated by the leader's ethicality. Appropriate ethical leadership should facilitate the relationship between workplace spirituality and desirable work intentions, while lack of ethical leadership should be detrimental to the same workplace spirituality-intentions relationship. It was also reasonable to suppose that the relationship between workplace spirituality and work intentions may not always be solely dependent on ethical leadership; rather, to some degree, workplace spirituality may directly influence employee work intentions.

Workplace spirituality research has previously demonstrated a positive relation with commitment, satisfaction, performance, productivity, and reduced absenteeism and turnover (Fry \& Nisiewicz, 2013; Jurkiewicz \& Giacalone, 2004; Karakas, 2010; Krishnakumar \& Neck, 2002). In furtherance of this line of research, the proposed study 
tested whether workplace spirituality has a predictive relation with the following work intentions: (a) intent to stay, (b) intent to use OCBs, (c) intent to use discretionary effort, (d) intent to endorse, and (e) intent to perform. The following subsections provide definitions and background for each of these dependent variable dimensions.

\section{Intent to Stay}

Intent to stay is defined as an employee's intention to remain within an organization (Zigarmi et al., 2012). Intent to stay or intent to leave/turnover was the most frequently cited construct of work intention in the studies that Zigarmi et al. (2012) reviewed as part of their development of the Work Intention Inventory scale. As intent to stay or intent to leave items are stated as true intentions, when the items are used

precisely, the construct was a strong predictor of attrition behavior, as well as correlating with other important outcome variables such as organizational commitment and job satisfaction (Zigarmi et al., 2012).

Intention to stay is the inverse concept of turnover intention. Intent to stay is defined as an employees' intention to stay with the present employer on long-term basis, while employee turnover is defined as an employee who may be thinking about quitting a job (Firth, Mellor, Moore, \& Loquet, 2004). Intention is a psychological precursor to the actual behavior act (Ajzen \& Fishbein, 1980), meaning that an individual's intention to perform a behavioral act or not precedes and influences the actual execution of the act. According to Dabke and Patole (2014) much has been written on voluntary employee turnover and intention to quit, however, in the age of positive Psychology, studying intention to stay seems to be the primary need of the hour. 


\section{Intent to Engage in Organizational Citizenship Behaviors}

Intent to use $O C B$ s is defined as an individual's intention to behave in ways that are respectful, considerate, and sensitive to others and which support the welfare and effectiveness of the organization (Zigarmi et al., 2012). These intentions are discretionary; they are neither found in most job descriptions nor explicitly recognized by a formal reward system. The OCB construct was the second most frequently studied area of work intention in the literature. There are strong correlations among most of the OCB dimensions, including altruism, sportsmanship, conscientiousness, and civic virtue, and outcome variables, such as job satisfaction, organizational commitment, and performance (LePine, Erez, \& Johnson, 2002; Organ \& Ryan, 1995; Posdacoff, MacKenzie, Moorman, \& Fetter, 1990). Various OCBs have been shown to correlate with antecedent variables, such as procedural justice, distributive justice, connectedness with leader, and meaningful work (Colquitt, Conlon, Wesson, Porter, \& Ng, 2001; LePine et al., 2002; Podsakoff, LePine, \& LePine, 2007).

The concept of OCB emerged in the field of organizational behavior through studies by Bateman and Organ (1983), which predicted a causal connection between overall satisfaction and subsequent display of citizenship behaviors. Its emergence was linked to Organ's (1977) suggestion that conventional measures of employee performance might not have included the entire domain of employee performance, calling for more judicious consideration. Organ $(1977,1988)$ specified OCBs as non-reward-seeking, organization-benefiting extra-role behaviors. These behaviors, to some extent, reflect an employee's transcendence of self-interests in that these behaviors are aimed at benefiting 
others without seeking any direct or point-for-point benefits for oneself in return (Pawar, 2009).

\section{Intent to Exert Discretionary Effort}

The intent to exert discretionary effort is defined as an employee's intention to expend efforts on behalf of the organization, above and beyond the agreed-upon requirements (Zigarmi et al., 2012). The concept of discretionary effort arose from the early research on OCBs by Smith, Organ, and Near (1983). Through their research, they elaborated on the nature of employees' behaviors that go beyond conformity with contractual roles or job descriptions, and demonstrate cooperation, helpfulness, and gestures of goodwill that contributed to the social fabric and ease of social interaction (Smith et al.,1983). In 1997, Organ updated his 20-year-old definition of OCB to "behaviors which support the social and psychological environment in which task performance takes place" (Organ, 1997, p. 95), removing the set of behaviors concerned with discretionary effort from the traditional definition of OCB. The literature shows little research concerning discretionary effort since 1997 (Zigarmi et al., 2012), however, the research that does exist shows that discretionary effort is positively correlated with the environmental antecedents of positive employee-coworker relationships and employee-manager relationships. Discretionary effort is also positively correlated with perceived psychological contract fulfillment, affective commitment to the job and organization, and engagement.

\section{Intent to Endorse}

Intent to endorse is defined as an employee's intention to endorse the organization to others as a good place to work and as a quality supplier of goods and services (Zigarmi 
et al., 2012). The concept of endorsement refers to the individual's uncritical faithfulness and connection to his or her organization. Endorsement implies employees' rise to the defense of the interests of the organization and desire to contribute to the good reputation and general welfare of the organization (Moorman \& Blakely, 1995). Endorsement is highly correlated with OCBs, and negatively correlated with cynicism (Andersson \& Bateman, 1997). Endorsement was found to be positively correlated with organizational commitment, organizational citizenship behaviors, trust in the organization, and trust in role performance (Chen, Aryee, \& Lee, 2005). Endorsement was also found to correlate with perceptions of procedural justice (Kamdar, McAllister, \& Turban, 2006).

\section{Intent to Perform}

Intent to perform is defined as an employee's intention to do their jobs at a higher than average level, thus effectively helping the organization succeed (Zigarmi et al., 2012). In the development of the Work Intention Inventory, the intent to perform construct had not been widely used, even though measures of engagement or work attitudes were used as independent variables and hard economic data and performance criteria were used as dependent variables (Zigarmi et al., 2012). Their research stated that it is reasonable to assert that engaged employees or employees passionate about their work, in the long run, perform well.

According to Fishbein and Ajzen (2010), as a general rule, when individuals have control over the performance of a behavior, they tend to act in accordance with their intentions. Additionally, when individuals intend to perform a behavior, they are more likely to persist if they believe they are capable of doing so. Consequently, self-efficacy is necessary, which provides that individuals have the skills and abilities to carry out the 
intended behavior (Fishbein \& Ajzen, 2010). This investigation adds to the work intentions research by examining the extent to which workplace spirituality and adequate leader ethical behaviors inspire work intentions that translate into positive organizational outcomes.

\section{Ethical Leadership}

Increasing numbers of scandals involving corporate and public sector leaders have made headlines since the early 1990s, feeding interest in ethical leadership (Brown \& Treviño, 2006). Ethical values and behavior are important aspects of several prominent theories in the literature on leadership, including servant leadership (Avolio \& Gardner, 2005; Liden, Wayne, Zhao, \& Henderson, 2008; Russell \& Stone, 2002; Smith, Montagno, \& Kuzmenko, 2004), spiritual leadership (Fry, 2003), authentic leadership (Gardner, Avolio, Luthans, May, \& Walumbwa, 2005), and transformational leadership (Den Hartog \& Belschak, 2012). Research on ethical leadership lagged behind other subjects for most of the 20th century, but since the 1990s, interest in studying the antecedents, outcomes, and processes of ethical leadership has been growing steadily (Ciulla, 2014).

Yukl, Mahsud, Hassan, and Prussia (2013) suggested that the construct domain of ethical leadership was broad, and several different types of values could be relevant including altruism, compassion, honesty, fairness, and justice. Examples of behaviors reflecting these values include being very supportive and helpful when someone has a problem, being fair when distributing rewards and benefits, being open and honest when communicating to people, making sacrifices to benefit others, talking about the importance of values, setting clear ethical standards for the work, keeping actions 
consistent with espoused values, and holding people accountable for ethical and unethical actions. Through their research, Yukl et al. found that ethical leadership was related to an effectiveness measure that included unit work performance provided evidence that being ethical is not only commendable but also effective.

For instance, Issa and Pick (2010) provided an example of how a culture of workplace spirituality was positively related to ethical mindsets as organizational members responded positively to values such as integrity, honesty, compassion, and trustfulness. Likewise, Beekun and Westerman (2012) concluded there was a positive correlation between spirituality in the workplace and the potential for ethical behavior. In an extended model of spiritual leadership, Fry (2005) proposed spiritual leadership facilitates ethical well-being and spiritual well-being at a personal level, and corporate social responsibility at an organizational level. The model Fry outlined suggested these outcomes are intermediate outcomes of employee experiences of calling and membership. Calling and membership, however, correspond to the meaning and community experiences included in workplace spirituality (Ashmos \& Duchon, 2000; Duchon \& Plowman, 2005; Pawar, 2009), suggesting employees' ethical well-being could be an outcome of their experiencing meaningful work and community aspects of workplace spirituality. This possible connection highlights the relevance of workplace spirituality to the ethical aspects of work, and the benefit of further inquiry on whether ethical leadership mediates the relation between workplace spirituality and work intention.

Corner (2009) suggested workplace spirituality "stimulates moral imaginations of people who have to deal with thorny ethical issues and provides rich information that 
better informs and supports an ethical decision making process" (p. 377). Scholars disagree on whether organizational ethicality originates from organizational ethical culture or organizational ethical climate. Treviño, Butterfield, and McCabe (1998) posited the constructs of ethical climate and ethical culture overlap, but remain different from each other. Treviño et al. (1998) explained the two constructs were different because of their metaphorical meanings and implications: ethical climate reflected normative characteristics and qualities that inform people regarding the organization and the values it holds, while ethical culture characterizes the organization in terms of formal and informal control systems that are aimed to more specifically influence behavior.

Therefore, the construct of organizational ethical culture better explains the ethical decision making and behavior of organizations and their members. Ardichvili, Mitchell, and Jondle (2009) noted the construct of organizational ethical culture had an impact on organizational behavior and ethical practice. According to Douglas, Davidson, and Schwartz (2001), the organizational ethical culture also played a role in discouraging unethical behavior. Empirical studies have reported organizational ethical culture had an effect on the moral sensitivity, awareness, judgment, motivation, and reasoning of organizational members. The reason for this effect is explained by the ethical aspect of organizational culture that refers to the principles of right and wrong within the organizational context, creating conditions that help explain and predict the (un)ethical behavior of managers and employees (Huhtala, Feldt, Lamsa, Mauno, \& Kinnunen, 2011).

Ethical culture might encourage or discourage ethical and unethical behavior; strong ethical cultures are more likely to produce less unethical behavior (Huhtala et al., 
2011). O'Fallon and Butterfield (2005), in their literature review study on ethical decision making, indicated ethical cultures greatly influence members' decision making. Researchers have begun to consider ethical leadership as a set of behaviors or a separate leadership style in itself rather than focusing only on the ethical components of other leadership styles (Brown et al., 2005; De Hoogh \& Den Hartog, 2008).

Brown et al. (2005) held that ethical leadership is a separate leadership style, and defined it as the demonstration of normatively appropriate conduct through personal actions and interpersonal relationships, and the promotion of such conduct to followers through two-way communication, reinforcement and decision making. In addressing ethical leadership from a social learning perspective, Brown et al. suggested followers come to behave similarly to their leaders through imitation and observational learning. In addition to this social learning approach, others have viewed ethical leadership from a social exchange approach (Mayer, Kuenzi, Greenbaum, Bardes, \& Salvador, 2009).

Scholars using a social exchange approach have focused more on the norm for reciprocity (Cropanzano \& Mitchell, 2005), and proposed followers tend to reciprocate when treated fairly and with concern by their leaders (Mayer et al., 2009).

\section{Summary}

This Chapter has highlighted and integrated several streams of research including: (a) workplace spirituality, (b) work intentions, and (c) ethical leadership. While workplace spirituality received increasing attention, what remains unclear is the linkage between workplace spirituality and work intentions. This linkage is critical to explore as workplace spirituality has been poorly linked to workplace intention and consequently behavior and outcomes - an emerging and important component of an employees' 
experience of their work. Moreover, very little is known about the influence of ethical leadership on workplace spiritualty. While a culture of workplace spirituality has been positively related to ethical mindsets in general, to date, no study has examined the influence of ethical leadership on the relationship between workplace spirituality and work intentions as a potential mediator.

As such, a hypothesized model of workplace spirituality, employee work intentions, and ethical leadership has been positioned and grounded in the research literature (See Figure 1, Chapter 3). In addition to informing theory building and future research, the practical implications of this model include fostering environments that embrace workplace spirituality as well as encourage ethical behavior, and by doing so, promote employee experiences that result in positive work intentions - ultimately impacting improved employee experiences and enhanced organizational performance. 


\section{CHAPTER III}

\section{METHODOLOGY}

A survey research design was used to examine the relationship among three dimensions of workplace spirituality: alignment with organizational values, meaningful work, and sense of community, and five dimensions of work intentions: intent to endorse, perform, stay, exert discretionary effort, and engage in organizational citizenship behaviors. Additionally, this study examined whether ethical leadership served as a mediator of the relationship between workplace spirituality and work intentions. This chapter discusses the research design and methodology, and is organized according to the following sections: (a) research questions and hypotheses; (b) population and sample; (c) variables and instrumentation; (d) controlling for survey errors; (e) data collection and analysis; and (f) assumptions and limitations.

\section{Research Questions and Hypotheses}

Two research questions were addressed:

RQ 1: What is the relationship between employees' workplace spirituality and work intentions?

H1 A: There is a relationship between employees' workplace spirituality and work intentions.

H10: There is no relationship between employees' workplace spirituality and work intentions. 
RQ 2: Does ethical leadership mediate the relationship between employees' workplace spirituality and work intentions?

H2A: Ethical leadership mediates the relationship between employees' workplace spirituality and work intentions.

$\mathrm{H} 2_{0}$ : Ethical leadership does not mediate the relationship between workplace spirituality and employee work intentions.

\section{Population and Sample}

The data sample of this study was based on 405 full-time employees in the United States who met the research criteria and completed the online survey instrument. According to a report by the Bureau of Labor Statistics (BLS), estimates of the U.S. workforce for 2015 reported that 106.6 million individuals were employed full-time, 27.3 million part-time, 8.3 million unemployed, and 15 million self-employed (U.S. Bureau of Labor Statistics, 2016). In line with the BLS definitions, full-time workers are individuals who, in general, work 35 hours or more per week. Self-employed individuals earn income through conducting profitable operations from a trade or business they operate directly, instead of working for an employer that pays a salary or wage. Moreover, a 2010 BLS report indicated that in 2010 only $83 \%$ of employees did some or all of their work at their workplace (U.S. Bureau of Labor Statistics, 2010). Given the intent of the study to examine data regarding employees' interactions and experiences in a workplace setting, two qualifying questions were employed to screen out respondents that were: (a) selfemployed, and (b) primarily worked from home (see Appendix A). BLS data estimated the demographic distribution of the full-time US workforce to be $42 \%$ females, $58 \%$ males, with $70 \%$ between the age range of 25 and 54. Race included: $12 \%$ African 
American; 6\% Asians; 17\% Hispanic or Latino; and 79\% White (U.S. Bureau of Labor Statistics, 2016).

To estimate the sample size, a power analysis was performed using the G*Power 3.1 statistical software (Faul, Erdfelder, Buchner, \& Lang \& 2009). The desired power was $0.80(80 \%)$, and a priori power analysis was conducted to compute the sample size, given power, alpha level, and effect size (Cohen, 1988). The accepted alpha level $(\alpha)$ was set at .05 . Both statistical power and alpha level were predetermined based on Cohen's (1988) suggestion that studies should be designed with an $80 \%$ probability of detecting an effect when there is an effect there to be detected, and no more than a $20 \%$ probability of making a Type II error. With the input parameters alpha at .05 ( $\alpha$ error probability), power at .80 (1- $\beta$ error probability), and effect size $r=.15$ for a small effect, the total sample size was calculated to be at least 346 respondents (Faul et al., 2009). This study proposed a sample size of 400 respondents, which exceeded the number suggested by the power analysis, as such, the sample size proposed was sufficient.

To make inferences about the subject population, nonprobability sampling was employed by means of a convenience sampling technique. Nonprobability sampling procedures are used to extend knowledge of the sample population (Uprichard, 2013). An advantage of using convenience sampling is the ease of recruitment of willing and available participants (Bornstein, Jager, \& Putnick, 2013). Additionally, convenience sampling strategies may be less costly than other sampling strategies, however the results of convenience sampling research may only be generalizable to the population of origin (Bornstein et al., 2013). The population for this research study consisted of individuals between the ages of 18 and 65, employed full-time in the United States; individuals who 
were self-employed and/or worked from home were eliminated. SurveyMonkey Audience (SMA), a survey participant panel, was employed to provide 400 completed responses from randomly selected participants who met the established criteria. For this study, full-time employees were deemed the most appropriate population as they interact with others in a workplace setting for at least 35 hours per week, and therefore are likely to possess information relevant to the three variables in the study. Participants could deny participation without penalty.

SurveyMonkey has taken several steps to ensure data quality. For example, according to SurveyMonkey, the issue of representative samples was minimized because of their ability to recruit from a group of more than 30 million people made up of the visitors to the SurveyMonkey site (SurveyMonkey, n.d.). Comparison tests carried out against similar research businesses such as Gallup revealed responses from the SMA matched the benchmarks in Gallup (SurveyMonkey, 2012). As such, representativeness of sample is ensured by performing periodical audience quality benchmarking tests to mitigate quality concerns regarding the data provided by respondents; test results are frequently compared with industry standards such as Gallup.

Moreover, to ensure service reliability, data and sample quality, SurveyMonkey (2012) is able to provide scale and diversity through a large database of respondents with diverse demographic profiles, with recruitment from various traffic sources and social networks. The use of validation tools, such as TrueSample ${ }^{\circledR}$, check for duplicate signups, verification of email address and physical location, as well as filtering tools to remove outliers and respondents who provide inaccurate data. 


\section{Variables and Instrumentation}

Key variables included participant demographics, which included personal and professional attributes, workplace spirituality, work intentions and ethical leadership. Workplace spirituality served as the independent variable with three levels: sense of community, alignment with organizational values, and meaningful work. Work intentions served as the dependent variable and consisted of five dimensions: intent to endorse, intent to perform, intent to stay, intent to use discretionary effort, and intent to use organizational citizenship behaviors. Finally, ethical leadership was included in the model as a mediator variable. Additionally, demographic data were collected from respondents for comparison with BLS data to verify that the random sample had characteristics in the same proportions as the population. Demographic variables included personal information of gender, race/ethnicity, household income, education and selfreported spirituality. Professional characteristics included tenure with current employer, job level and industry (see Appendix E). Table 2 displays the list of demographic variables on respondents' personal and professional attributes. The next section describes key variables in detail.

Table 2

Participants Personal and Professional Attributes

\begin{tabular}{lll}
\hline Variable & $\begin{array}{l}\text { Scale of } \\
\text { Measurement }\end{array}$ & Coding \\
\hline Gender & $\begin{array}{l}\text { Categorical } \\
\text { (nominal), } \\
\text { levels }\end{array}$ & $1=$ Female; 2 = Male; $3=$ Other \\
Race/ Ethnicity & $\begin{array}{l}\text { Categorical } \\
\text { (nominal), } 6 \\
\text { levels }\end{array}$ & $\begin{array}{l}1=\text { American Indian or Alaskan Native; } 2= \\
\text { American; } 4 \text { = Hispanic or Latino; } 5=\text { White / } \\
\text { Caucasian; } 6 \text { = Two or More Races }\end{array}$
\end{tabular}




\begin{tabular}{|c|c|c|}
\hline Variable & $\begin{array}{l}\text { Scale of } \\
\text { Measurement }\end{array}$ & Coding \\
\hline $\begin{array}{l}\text { Annual } \\
\text { Household } \\
\text { Income }\end{array}$ & $\begin{array}{l}\text { Categorical } \\
\text { (ordinal), } 11 \\
\text { levels }\end{array}$ & $\begin{array}{l}1=\$ 0-\$ 24,999 ; 2=\$ 25,000-\$ 49,999 ; 3= \\
\$ 50,000-\$ 74,999 ; 4=\$ 75,000-\$ 99,999 ; 5= \\
\$ 100,000-\$ 124,999 ; 6=\$ 125,000-\$ 149,999 ; 7 \\
=\$ 150,000-\$ 174,999 ; 8=\$ 175,000-\$ 199,999 ; \\
9=\$ 200,000-\$ 224,999 ; 10=\$ 225,000- \\
\$ 249,999 ; 11=\$ 250,000 \text { and up }\end{array}$ \\
\hline Spirituality & $\begin{array}{l}\text { Categorical } \\
\text { (ordinal), } 5 \\
\text { levels }\end{array}$ & $\begin{array}{l}1=\text { Not at all spiritual; } 2=\text { Slightly spiritual; } 3 \\
=\text { Unsure; } 4=\text { Moderately spiritual; } 5=\text { Very } \\
\text { spiritual }\end{array}$ \\
\hline $\begin{array}{l}\text { Highest level of } \\
\text { education }\end{array}$ & $\begin{array}{l}\text { Continuous } \\
\text { (ordinal), } 6 \\
\text { levels }\end{array}$ & $\begin{array}{l}1=\text { Less than high school degree; } 2=\text { High } \\
\text { school degree or equivalent (e.g., GED); } 3= \\
\text { Some college but no degree; } 4=\text { Associate } \\
\text { degree; } 5=\text { Bachelor degree; } 6=\text { Graduate } \\
\text { degree }\end{array}$ \\
\hline $\begin{array}{l}\text { Years of tenure } \\
\text { with current } \\
\text { employer }\end{array}$ & $\begin{array}{l}\text { Categorical } \\
\text { (ordinal), } 6 \\
\text { levels }\end{array}$ & $\begin{array}{l}1=1-3 ; 2=4-6 ; 3=7-9 ; 4=10-12 ; 5=13-15 ; \\
6=\text { more than } 16\end{array}$ \\
\hline Current job level & $\begin{array}{l}\text { Categorical } \\
\text { (ordinal), } 5 \\
\text { levels }\end{array}$ & $\begin{array}{l}1=\text { Senior Management; } 2=\text { Mid-Career; } 3= \\
\text { Intermediate; } 4=\text { Entry Level; } 5=\text { Other }\end{array}$ \\
\hline Principal Industry & $\begin{array}{l}\text { Categorical } \\
\text { (nominal), } 21 \\
\text { levels }\end{array}$ & $\begin{array}{l}1=\text { Advertising \& Marketing; } 2=\text { Agriculture; } \\
3 \text { = Airlines \& Aerospace (including Defense); } \\
4=\text { Automotive; } 5=\text { Business Support } \& \\
\text { Logistics; } 6=\text { Construction, Machinery, and } \\
\text { Homes; } 7=\text { Education; } 8=\text { Entertainment } \& \\
\text { Leisure; } 9=\text { Finance \& Financial Services; } 10 \\
\text { = Food \& Beverages; } 11=\text { Government; } 12= \\
\text { Healthcare \& Pharmaceuticals; } 13= \\
\text { Insurance; } 14=\text { Manufacturing; } 15= \\
\text { Nonprofit; } 16=\text { Retail \& Consumer Durables; } \\
17=\text { Real Estate; } 18=\text { Telecommunications, } \\
\text { Technology, Internet \& Electronics; } 19= \\
\text { Transportation \& Delivery; } 20=\text { Utilities, } \\
\text { Energy, and Extraction; } 21=\text { Other }\end{array}$ \\
\hline
\end{tabular}




\section{Workplace Spirituality}

Workplace spirituality refers to the recognition that employees have an inner life that nourishes and is nourished by meaningful work taking place in the context of community (Ashmos \& Duchon, 2000). Workplace spirituality was operationalized using 19-items selected from pre-existing instruments (see Appendix B). In particular, 12 items representing the subscales of meaningful work and alignment with organizational value were adopted from the Spirituality at Work scale (Ashmos \& Duchon, 2000). The additional 7 items were developed by Milliman and colleagues and assessed sense of community (Milliman et al., 2003). The purpose of the scale is to measure workplace spirituality for research and practical purposes, expanding knowledge on how employees interact with their employer, work, and colleagues, and how they identify with the mission, values and goals of the organization. Responses were captured using a 7-point Likert scale, anchored with $1=$ strongly disagree and $7=$ strongly agree .

In the development of the Spirituality at Work scale, Ashmos and Duchon (2000) extracted seven dimensions of workplace spirituality via a principal components factor analysis. Two of these dimensions, meaningful work and alignment with organizational values, were adopted for this study. Meaningful work included five of the seven original items measured by Ashmos and Duchon (2000); items with factor loading greater than .50 were selected. Internal consistency reliability (coefficient alpha) assessed in previous studies indicated acceptable levels at $\alpha=.86$ (Ashmos \& Duchon, 2000), $\alpha=.88$ (Milliman et al., 2003), and $\alpha=.86$ (Duchon \& Plowman, 2005). An example item is "I experience joy in my work". The subscale of alignment with organizational values included seven original items measured by Ashmos and Duchon (2000); the coefficient 
alphas in previous studies indicated acceptable levels of reliability at $r=.93$ (Ashmos \& Duchon, 2000), and $r=.94$ (Milliman et al., 2003). An example item is "This organization has a conscience: a high regard for morality and right conduct." The third subscale, sense of community, was adopted from subsequent work from Milliman et al. (2003), whose confirmatory factor analysis supported the subscale's unidimensionality. The alpha coefficient reported in previous studies was $r=.91$ (Milliman et al., 2003). An example item is "I believe people support each other in my work environment."

\section{Work Intentions}

Work intentions were measured using the work intention inventory-short form (Nimon \& Zigarmi, 2015). The purpose of the scale is to assess a set of five work intentions resulting from employees' state of well-being, or lack thereof (Nimon \& Zigarmi, 2015). Validation evidence for the work intention inventory was established over the course of two studies, with a research design that followed a sequential exploratory-confirmatory procedure in order to examine, refine, and confirm the factor structure of the scales (Nimon \& Zigarmi, 2015; Zigarmi et al., 2012). The exploratory factor analysis employed principal axis factoring and promax rotation due to a hypothesized underlying theoretical structure of correlated factors; the confirmatory factor analysis employed the maximum likelihood estimation technique for testing the models. The five subscales demonstrated acceptable factor structure and reliability.

The short-form of the work intentions instrument consisted of 15 items (see Appendix C); responses were captured on a 7-point Likert-type scale, ranging from $1=$ No Extent to $7=$ To The Fullest Extent, and indicated the extent to which participants intended to engage in the described work intentions. Example statement items included: 
"I intend to continue to work for my current organization because I believe it is the best decision for me", for intent to stay; "I intend to respect this organization's assets" for intent to engage in OCB; "I intend to exert the energy it takes to ensure I do my job well" for intent to perform; "I intend to spend my discretionary time finding information that helps my organization" for intent to exert discretionary effort, and "I intend to speak out to protect the reputation of my organization" for intent to endorse. The subscale scores were calculated by taking the average score of the items. Previous studies reported acceptable alpha coefficients ranging from .82 to .94 (Nimon \& Zigarmi, 2015), and .87 to .96 (Zigarmi et al., 2012).

\section{Ethical Leadership}

Ethical leadership was measured via 15 items from the Ethical Leadership Questionnaire (ELQ; see Appendix D; Yukl, Mahsud, Hassan, \& Prussia, 2013). The purpose of the ELQ was to measure essential aspects of ethical leadership independently of other types of leader behavior that did not directly involve ethical issues; as such, the ELQ items minimized confounding with other constructs or overlap with other leadership behaviors. The items describe aspects of ethical leadership, including honesty, integrity, fairness, altruism, consistency of behaviors with espoused values, communication of ethical values, and ethical guidance. Exploratory and confirmatory factor analyses were used to assess discriminant validity for the ELQ. Both exploratory and confirmatory factor analysis confirmed that the items in the ELQ are distinct from task- and changeoriented leader behaviors, and there is minimal overlap with relations-oriented leader behaviors such as supportive and empowering leadership. Additionally, confirmatory factor analytic findings supported the study's proposed model and showed adequate fit 
given the number of indicators per construct. All items on the scale were measured using a 7-point Likert scale $(1=$ strongly disagree, $7=$ strongly agree $)$. An example item is "My boss insists on doing what is fair and ethical even when it is not easy." The study by Yukl and colleagues (2012) demonstrated that the ELQ had high reliability as well as discriminant and criterion-related validity. Alpha coefficients in previous studies have been reported at $\alpha 0.96$ (Hassan, Mahsud, Yukl, \& Prussia, 2013; Hassan, Wright, \& Yukl, 2014; Yukl et al., 2013). The total score of the scale was calculated by taking the average score of the items and served as a global indicator with one composite score of ethical leadership.

The Cronbach's alpha coefficient statistic provides an indication of the average correlation among all of the items that make up the scale; values range from 0 to 1 , with higher values indicating greater reliability. As a measure of internal consistency and reliability, a Cronbach Alpha statistic of .80 or greater was considered an acceptable reliability coefficient, as suggested for basic research purposes (Henson, 2001; Nunnally, 1967). The various instruments selected for each section of the survey and the variables they examine in this study are identified in Table 3.

Table 3

Selected Instruments and Reliability Statistics of Survey Items

\begin{tabular}{lccll}
\hline $\begin{array}{l}\text { Instrument } \\
\text { section }\end{array}$ & $\begin{array}{c}\text { Items } \\
(n)\end{array}$ & $\begin{array}{c}\text { Variable(s) } \\
\text { measured }\end{array}$ & Source of items & $\begin{array}{c}\text { Reported Cronbach's } \\
\text { alpha }\end{array}$ \\
\hline $\begin{array}{l}\text { Workplace } \\
\text { Spirituality }\end{array}$ & 7 & Sense of community & Milliman et al., 2003 & .91 \\
$\begin{array}{l}\text { Workplace } \\
\text { Spirituality }\end{array}$ & 5 & Meaningful work & $\begin{array}{l}\text { Ashmos \& Duchon, } \\
2000\end{array}$ & .88 \\
$\begin{array}{l}\text { Workplace } \\
\text { Spirituality }\end{array}$ & 7 & $\begin{array}{l}\text { Alignment with } \\
\text { organizational values }\end{array}$ & $\begin{array}{l}\text { Ashmos \& Duchon, } \\
2000\end{array}$ & .94
\end{tabular}




\begin{tabular}{|c|c|c|c|c|}
\hline $\begin{array}{l}\text { Instrument } \\
\text { section }\end{array}$ & $\begin{array}{l}\text { Items } \\
(n)\end{array}$ & $\begin{array}{l}\text { Variable(s) } \\
\text { measured }\end{array}$ & Source of items & $\begin{array}{c}\text { Reported Cronbach's } \\
\text { alpha }\end{array}$ \\
\hline $\begin{array}{l}\text { Work } \\
\text { Intentions }\end{array}$ & 15 & $\begin{array}{l}\text { Intent to stay; use } \\
\text { OCBs; use } \\
\text { discretionary effort; } \\
\text { endorse; perform }\end{array}$ & $\begin{array}{l}\text { Nimon \& Zigarmi, } \\
2015\end{array}$ & $\begin{array}{l}.91 \text { (stay); } .94 \\
\text { (OCB); .82 (effort); } \\
.93 \text { (endorse); .90 } \\
\text { (perform) }\end{array}$ \\
\hline $\begin{array}{l}\text { Ethical } \\
\text { Leadership }\end{array}$ & 15 & & Yukl et al., 2013 & $\begin{array}{l}.96, \text { ethical } \\
\text { leadership }\end{array}$ \\
\hline
\end{tabular}

Prior to conducting the research activities beyond the literature review and development of a research design, approval was obtained from the Human Subjects Committee of the University of Louis ville Internal Review Board (see Appendix F). An informed consent form, approved by the University of Louis ville Internal Review Board, was provided to potential participants as an overview of the study, as well as explain possible risks to respondents (see Appendix G). SMA members who meet the study participant criteria received an invitation to participate in the study and were provided a copy of the informed consent form. Clicking on the link to access the survey served as implied informed consent.

\section{Controlling for Survey Errors}

According to Dillman, Smyth, and Christian (2014), surveyors need to minimize four main types of errors to improve the survey estimates: coverage error, sampling error, measurement error, and nonresponse error. Coverage error occurs when the list from which sample members were drawn does not accurately represent the population on the characteristics one wants to estimate with the survey data; this type of error is minimized when each member of a defined population has an equal chance of being surveyed (Dillman, Smyth, \& Christian, 2014). The composition of Internet-recruited samples differs from the underlying population because it is estimated that $33 \%$ of the U.S. adult 
population does not use the Internet on a regular basis (Baker et al., 2013). As such, part of the population without Internet access cannot be included in the sample. Another difference between Internet-recruited samples and the general population is that Internet panel members tend to be more educated and have higher socioeconomic status than do non-panel members (Baker et al., 2013). As such, coverage error will result in a limitation of the study: inability for generalization to populations outside of the Internet user community (Fricker, 2008).

Sampling error occurs when only some, rather than all, members of the sample frame are surveyed (Dillman et al., 2014). As such, sampling error represents a potential limitation of this due to the observation that Survey Monkey Audience respondents represent a diverse group of individuals and are reflective of the general population; however, as with most online sampling, respondents have Internet access and voluntarily joined a program to take surveys (SurveyMonkey.com, n.d.). Additionally, the SurveyMonkey system includes stratified sampling to attain various types of respondents, including active and less active panelist (SurveyMonkey, 2013); stratification typically decreases sampling error (Dillman et al., 2014). Using an adequate sample size, as proposed for this study, also helps reduce sampling error.

Measurement error occurs when respondents are unable or unwilling to provide accurate answers, which can be due to poor question design, survey mode effects, interviewer and respondent behavior, or data collection mistakes (Dillman et al., 2014). One approach to reduce measurement error in this study was the use of a pre-existing survey with previously reported psychometric evidence of scores. Additionally, SurveyMonkey Audience limits the number of surveys a member can complete in a week 
and provides non-monetary incentives to encourage high-quality responses and discourage lack of attention and effort. As such, survey participants had the opportunity to designate a charity of choice to receive a donation of $\$ .50$ per survey completion, and were entered to win weekly sweepstakes of $\$ 100$ gift card prizes (SurveyMonkey, 2013).

Finally, nonresponse error occurs when those who do not respond are different from those who do respond in a way that influences the estimate (Dillman et al., 2014). Nonresponse error was minimized via non-monetary incentives (donations and sweepstakes entries), encouraging high-quality responses and discouraging lack of attention and effort (Brandon, Long, Loraas, Mueller-Phillips, \& Vansant, 2013). Additionally, demographic data collected from respondents was compared to BLS demographics to ensure sample is a good representation of the larger population.

\section{Data Collection and Analysis}

Data collection took place beginning on January $29^{\text {th }}, 2016$, and remained open until the established number of at least 400 usable responses were obtained. The research participants were randomly selected from the SurveyMonkey Audience respondent pool, which included more 3 million participants (Surveymonkey, 2013).

Data analysis began with the use of data screening procedures to inspect for data quality. This included, for example, screening for: missing values, outliers, normality, linearity, and multicollinearity. Missing values were evaluated via Little's MCAR test (Little \& Rubin, 2002). Outliers were evaluated via Z-scores to ensure that data were within acceptable limits. Considering absolute values, in a normal distribution about $5 \%$ of the data was expected to have values greater than 1.96 , and $1 \%$ to have absolute values greater than 2.58, and none to be greater than about 3.29 (Tabachnick \& Fidell, 2007). 
Normality was evaluated via histograms and Q-Q plots, in addition to skewness and kurtosis. According to Bulmer (1979), skewness greater than 1 in absolute value is considered highly skewed; a skewness between 1 and 1/2 moderately skewed; and a distribution with skewness between 0 and $1 / 2$ is considered fairly symmetrical. Tabachnick and Fidell (2013) suggested an acceptable range for skewness or kurtosis below +1.5 and above -1.5 .

The assumption of linearity assumes the relationship between the independent and dependent variables to be linear (Cohen \& Cohen, 1983). This study utilized a linear model and thus linearity was assumed. Linearity was evaluated via residual data in the residual histogram and P-P plot. As suggested by Field (2009), the P-P plot provides a complementary visual evaluation of normal distribution, and based on the evaluation normality of distribution and linearity was assumed. Homoscedasticity is the assumption that the variability in scores for one variable is roughly the same at all values of the other variable; when normality is not met, variables are not homoscedastic (Cohen \& Cohen, 1983; Green 1991). The Durbin-Watson test was utilized to evaluate independence of errors. According to Field (2009), values less than 1 or greater than 3 would be cause for concern. Homoscedasticity was also tested visually, observing residuals via bivariate scatterplot and examined for an oval shape versus a cone or funnel shape (Green, 1991). An oval shape provided evidence that the variance of residual error was constant for all values within the variables.

Finally, multicollinearity was assessed by evaluating the correlation coefficients in the correlation matrix and the Variance Inflation Factor (VIF). Multicollinearity occurs when variables are correlated and, thus, making it difficult to obtain reliable estimates of 
regression parameter estimates (Cohen \& Cohen, 1983). Field (2009) suggested that predictors that correlate too high to each other $(r>.9)$ may be of concern in regards to multicollinearity. Variance Inflation Factor (VIF) scores were also evaluated for multicollinearity. VIF statistically quantified the degree of multicollinearity between variables by providing an index that estimates how much variance is inflated due to collinearity (Green, 1991). Although there is no set rule of thumb to compare numerical values on VIF, it is suggested that multicollinearity is indicated through VIF values that exceed 10 (Green, 1991; Myers, 1990)

After data screening, descriptive statistics were used to report measures of central tendency and variability such as means and standard deviation. Subsequent, correlations were estimated to address Research Question 1 and examine the plausibility of hypothesized relationships between workplace spirituality and work intentions (Gall, Borg, \& Gall, 1996). To assess the second research question, path analysis was used to determine if a third variable, a mediator, influenced the relationship between the independent and dependent variables. Path analysis estimated the relationships in the assumed theory, in particular the strength and direction of the relationships, or whether the relationships were not supported by the data (Cook \& Campbell, 1979).

According to Creswell (2012), in correlational research designs, investigators use the correlation statistical test to describe and measure the degree of association (or relationship) between two or more variables. To answer the first research question and test the first pair of hypotheses, a Pearson Product-Moment correlations were calculated between workplace spirituality and work intentions. The effect size interpretation for the 
correlations followed Cohen's (1988) criteria: $\geq .10=$ small; $\geq .30=$ moderate; and $\geq .50=$ strong.

The hypothesized path analysis model included three exogenous variables (workplace spirituality, age and gender), and two endogenous variables (ethical leadership and employee work intentions). The path model aimed to explore the indirect effect, the mediating role of ethical leadership on the relation between workplace spirituality on employee work intentions. The indirect effect measures the extent to which the dependent variable changes when the independent variable is held fixed; and the mediator variable changes by the amount it would have changed had the independent variable increased by one unit (Judd \& Kenny, 1981). Based on previous research (Ashmos \& Duchon, 2000; Milliman et al, 2003), this study hypothesized that higher levels of workplace spirituality would be associated with higher levels of employee work intentions, and ethical leadership as a potential mediator of that relationship.

For the path analysis, model fit evaluation followed suggestions from Kline (2005), determined by the chi-square goodness-of-fit statistic $\left(\chi^{2}\right)$, which indicated the extent to which the original and estimated matrices are similar, therefore, a nonsignificant value was desirable. Since the power of the chi-square test is sensitive to the sample size and the size of correlations (Kline, 2005), the relative chi-square (CMIN/DF) was also reported; this index should not exceed a value of three (Schermelleh-Engel, Moosbrugger, \& Müller, 2003). Additional criteria utilized to evaluate the model fit included the root mean square error of approximation (RMSEA), which tested the null hypothesis for poor fit and should not be higher than 0.06 (Hu \& Bentler, 1999). The Bentler comparative fit index (CFI) compared the existing model fit with a null model 
and should at least reach a value of 0.95 . And finally, goodness-of-fit tests comparing the given model with an alternative model and the generalized squared multiple correlation $\left(R^{2}\right)$ (Schumacker \& Lomax, 2010).

The path analysis utilized bias-corrected bootstrap confidence intervals criteria to estimate the statistical significance of the indirect effects (Hayes 2013). The indirect effect, the product of path coefficients "a" workplace spirituality and "b" ethical leadership, and confidence intervals were estimated using AMOS user-defined estimands (Arbuckle, 2016). There are two methods for calculating the confidence interval of an indirect effect and for testing an indirect effect for significance. Sobel's $(1982,1986)$ method assumes that the indirect effect is normally distributed. A growing body of statistical literature calls into question this assumption, and advocates the use of the bootstrap procedure to construct better confidence intervals (MacKinnon, Lockwood, \& Williams, 2004; Shrout \& Bolger, 2002). These studies found that the bias-corrected bootstrap confidence intervals generate reliable inferences for indirect effects.

The bootstrap resampling procedures were set at 2000 samples with a biascorrected confidence interval set at $95 \%$. According to Hayes (2013), this method is widely recommended for inference about indirect effects in mediation analyses, as it balances validity and power considerations. The selection of the method to determine the indirect effects was based on precautionary concerns for Type I (claiming an indirect effect exists when it does not), and Type II (failing to detect an indirect effect that is real) errors (Hayes 2013). The bootstrapping method was employed to generate an empirically derived representation of the sampling distribution of the indirect effect, and this empirical representation was used for the construction of a confidence interval for $a b$. 
Bootstrap bias-corrected confidence intervals better respect the irregularity of the sampling distribution of $a b$ and, as a result, produce inferences that were more likely to be accurate (Hayes, 2013). All analyses were conducted using the Statistical Package for the Social Sciences (SPSS) and SPSS AMOS 24.

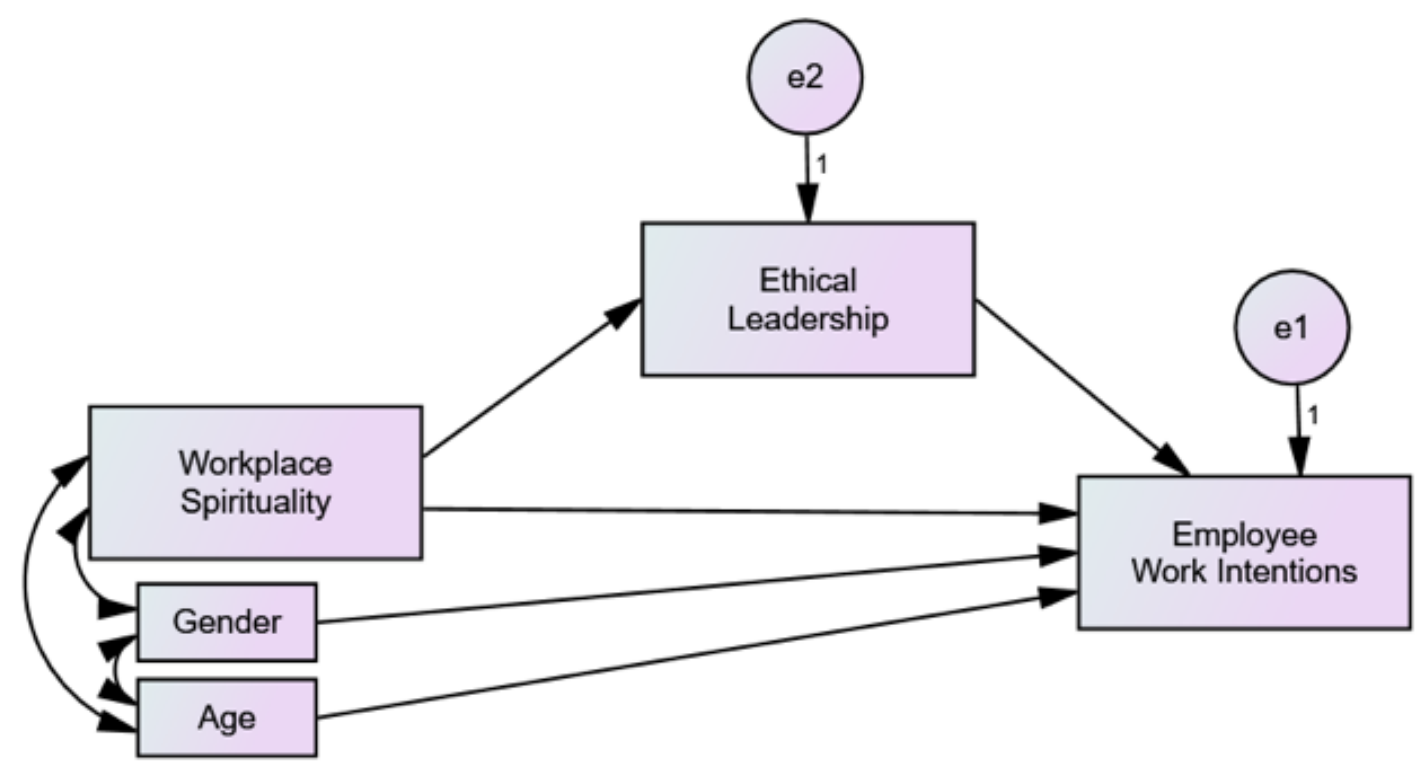

Figure 1. Proposed path analysis of the hypothesized relationship between workplace spirituality, work intentions and mediation through ethical leadership.

\section{Assumptions and Limitations}

The purpose of this research was to assess the relationship among three dimensions of workplace spirituality and five dimensions of work intentions, and examine for a potential mediating role of ethical leadership. The assumptions made regarding this study included: (a) no researcher bias to hamper participant response; (b) researcher did not interact with the respondents; (c) respondents were guaranteed anonymity, and (d) participants' responses were honest and reflected their experiences in the workplace. 
As with any research, there were limitations to this study. A key limitation of the study involves the ability to generalize the findings to the larger population. According to Thompson and Perry (2004), action research can be generalized to a larger population if, while acknowledging that only working hypotheses can be abstracted from the research, the research contains enough descriptive information that it can be duplicated in differing circumstances, and it can be demonstrated the data are reliable and confirmable. Blair and Zinkhan (2006) stated generalizability must meet three criteria: (a) the research must confirm or reject a hypothesis previously stated rather than confirming something found in a good sample; (b) there is a good sample with a low nonresponse bias; and (c) the ability to replicate the study and reach the same findings, showing that the study results are not a fluke. Threats to internal validity are considered the most severe validity threats because it can compromise an otherwise good experiment; one such threat to this study relates to the temporal precedence and lack of clarity about which variable occurred first (Shadish, Cook, \& Campbell, 2002). This study assumed that the independent variable preceded the dependent variable in time.

Another key limitation relates to coverage error. This study utilized Internet opted-in panels. As such, individuals without Internet access, and the population with internet access that did not opt into the SMA panels were prevented from being included in the sample. According to Baker et al. (2013), an estimated $30 \%$ of the U.S. adult population does not use the Internet on a regular basis, as such, part of the population without Internet access cannot be included in the sample. Furthermore, panel members tend to be more educated and have higher socioeconomic status than do non-panel members (Baker et al., 2013). 
Findings of this study may be susceptible to common method variance as it is based on self-reported data. There is sufficient support for the proposition that in work settings people's self-impressions are magnified by a common tendency to self-enhance, and they tend to view themselves more positively than appraisals of them from other sources (Podsakoff \& Organ, 1986). In the assessment of ethical leadership, the supervisory relationship posed a limitation of respondent's best assumption when answering survey items. The length of the supervisory relationship was not considered. Furthermore, an employee's assessment of leader ethicality could have been influenced by the respondent's perception of the overall leadership of the organization. Thus, future research would benefit from considering multi-source measurement of the variables, including ratings from subordinates and superiors, as well as self-ratings. Despite these limitations, the results should provide some original findings, and make a contribution to the ongoing research and the development of organizational theory related workplace spirituality and its association with employee work intentions and ethical leadership. 


\section{CHAPTER IV}

\section{RESULTS}

The purpose of this correlational study was to assess the predictive relationship between workplace spirituality and employee work intentions, and whether ethical leadership mediated the hypothesized relationship. The study was designed to answer the following two research questions:

RQ 1: What is the relationship between employees' workplace spirituality and work intentions?

RQ 2: Does ethical leadership mediate the relationship between employees' workplace spirituality and work intentions?

This chapter reports the results of the study. It begins with a discussion of the background of the sample demographics and descriptive statistics. The results section continues with a discussion of preliminary screening of data, followed by correlation and path analysis and a concluding summary.

\section{Background of the Sample}

A total of 663 participants took part in the survey; 231 participants self-reported as self-employed $(n=158)$ or working from home $(n=73)$ and were disqualified based on screening criteria. Z-scores evaluations determined four respondents were contributing to outlier data; data screening also identified 23 respondents with missing data, which were determined to be missing completely at random (MCAR) and removed. Data analysis proceeded with a complete case analysis of 405 surveys, or $61 \%$ of total 
participants. The data sample was composed of $49 \%$ males, and $51 \%$ females; $78 \%$ of between the ages of 25 and 54. More than 50\% reported tenure with current employer between 1 and 6 years. Racial diversity was represented by 8\% African American; 4\% Asian; 7\% Hispanic or Latino; and 77\% whites. Table 4 contains a summary of participant demographics.

Table 4

Respondents Personal and Professional Attributes

\begin{tabular}{llrr}
\hline Demographic & Values & Frequency & Percent \\
\hline Gender & Female & 207 & 51.1 \\
& Male & 198 & 48.9 \\
\hline Age & $18-24$ & 36 & 8.9 \\
& $25-34$ & 114 & 28.1 \\
& $35-44$ & 103 & 25.4 \\
& $45-54$ & 97 & 24.0 \\
& $55-64$ & 54 & 13.3 \\
& 65 or older & 1 & 0.2 \\
\hline Education & Less than high school & 5 & 1.2 \\
(Highest & High school or equivalent & 59 & 14.6 \\
Degree) & Some college, but no degree & 92 & 22.7 \\
& Associate's degree & 61 & 15.1 \\
& Bachelor's degree & 133 & 32.8 \\
& Graduate degree & 55 & 13.6 \\
\hline Race/Ethnicity & American Indian or Alaskan Native & 4 & 1.0 \\
& Asian/Pacific Islander & 14 & 3.5 \\
& African American & 33 & 8.1 \\
& Hispanic or Latino & 29 & 7.2 \\
& White/Caucasian & 311 & 76.8 \\
& Two or More Races & 14 & 3.5 \\
\hline Hours Worked & Up to 29 & 11 & 2.7 \\
per Week & $30-34$ & 23 & 5.7 \\
& $35-44$ & 269 & 66.4 \\
& $45-59$ & 90 & 22.2 \\
& More than 60 & 12 & 3.0 \\
\hline Annual & \$0-\$24,999 & 33 & 8.1 \\
Household & \$25,000-\$49,999 & 115 & 28.4 \\
Income & \$50,000-\$74,999 & 102 & 25.2 \\
& \$7,000-\$99,999 & 82 & 20.2 \\
& \$100,000-\$124,999 & 38 & 9.4
\end{tabular}




\begin{tabular}{llrr}
\hline Demographic & Values & Frequency & Percent \\
& \$125,000-\$149,999 & 19 & 4.7 \\
& \$150,000 and up & 16 & 3.8 \\
\hline Tenure with & $1-3$ years & 139 & 34.3 \\
employer & $4-6$ years & 75 & 18.5 \\
& $7-9$ & 55 & 13.6 \\
& $10-12$ & 43 & 10.6 \\
& $13-15$ & 27 & 6.7 \\
& 16 or more & 66 & 16.3 \\
\hline Job Level & Senior management & 37 & 9.1 \\
& Mid-Career & 137 & 33.8 \\
& Intermediate & 142 & 35.1 \\
& Entry Level & 61 & 15.1 \\
& Other & 28 & 6.9 \\
\hline Principal & Advertising \& Marketing & 2 & 0.5 \\
Industry & Agriculture & 3 & 0.7 \\
& Airlines \& Aerospace (incl. defense) & 6 & 1.5 \\
& Automotive & 4 & 1.0 \\
& Business Support \& Logistics & 9 & 2.2 \\
& Construction, Machinery, and Homes & 25 & 6.2 \\
& Education & 44 & 10.9 \\
& Entertainment \& Leisure & 7 & 1.7 \\
& Finance \& Financial Services & 20 & 4.9 \\
& Food \& Beverages & 25 & 6.2 \\
& Government & 19 & 4.7 \\
& Healthcare \& Pharmaceuticals & 10.4 \\
& Insurance & 2.5 \\
& Manufacturing & 10 & 7.7 \\
Nonprofit & 31 & 4.0 \\
& Retail \& Consumer Durables & 16 & 7.7 \\
& Real Estate & 31 & 0.5 \\
& Telecom., Tech., Internet \& Electronics & 22 & 5.4 \\
& Transportation \& Delivery & 4.0 \\
& Utilities, Energy, and Extraction & 16 \\
\hline Other & &
\end{tabular}

Note: $N=405$

\section{Data Analysis}

\section{Descriptive Statistics}

Descriptive statistics including mean and standard deviation, correlations, and internal consistency reliability for the measures of workplace spirituality, ethical 
leadership, and employee work intentions are reported in Table 5. The scales selected for the study possessed good internal reliability ( $\alpha=.94$ to .98$)$, with coefficients above .8 , as considered acceptable for general research purposes (Henson, 2001; Nunnally, 1967). Examination of the mean scores indicated means were above the 3.5 scale midpoint for the three variables. Respondents rated ethical leadership highest $(M=5.20, S D=1.52)$, followed by workplace spirituality $(M=5.03, S D=1.18)$ and work intentions $(M=4.78$, $S D=1.25)$. Correlations among the variables were positive and significant at the .01 level, ranging between .61 and .79, considered strong (>.50) according to Cohen's (1988) criteria. The strong positive correlation suggested that if workplace spirituality increases, work intentions would follow in tandem, and if workplace spirituality decreased, so would work intentions.

Table 5

Descriptive Statistics and Correlations for Ethical Leadership, Workplace Spirituality and Work Intentions

\begin{tabular}{lccccc}
\hline & $\begin{array}{c}\text { Cronbach's } \\
\text { Alpha }\end{array}$ & Mean (SD) & Range & \multicolumn{2}{c}{ Correlations } \\
\cline { 5 - 6 } 1. Ethical Leadership & 0.98 & $5.20(1.52)$ & 1 to 7 & - & 2 \\
2. Workplace Spirituality & 0.96 & $5.03(1.18)$ & 1 to 7 & 0.70 & - \\
3. Work Intentions & 0.94 & $4.78(1.25)$ & 1 to 7 & 0.61 & 0.79 \\
\hline
\end{tabular}

Note: $N=405 ; S D=$ Standard Deviation

Although the intercorrelations among the global scales were strong, they did not exceed the threshold of $r>.9$ regarding potential concerns for multicollinearity (Field, 2009). Additionally, the highest inter-predictor variable correlation occurred between sense of community and alignment with organizational values $(r=.734, p>.01)$. VIF statistics were also calculated to examine for multicollinearity. The highest VIF value calculated for this model was 2.236; VIF statistics near or greater than 10 are generally 
regarded as indicating multicollinearity (Green, 1991; Myers, 1990). Based on the observed correlations values and VIF statistics, multicollinearity was not a concern for this sample.

In addition examining for multicollinearity, prior to proceeding with Pearson Product-Moment correlation ( $r$ ) analysis, the data set was also examined for missing values and outliers, and the assumptions of normality, linearity. First, data were screened for missing responses for the 432 respondents who met the study criteria; 23 records with non-response missing data at the item level were identified. Respondents either intentionally declined to answer an item or mistakenly missed one or more responses. To determine the data were missing completely at random, and unrelated to any of the variables involved the analysis, Little's MCAR test was performed (Little \& Rubin, 2002). The test results for this data set obtained a chi-square $=556.77(d f=529 ; p=$ .195), a non-significant result, indicating that missing items were found to be MCAR; as such, a complete case analysis would be unbiased, and the 23 records with missing data were removed from the data set. Second, data were inspected for outliers. Z-scores were calculated and evaluated to ensure that data were within acceptable limits. The five data points listed in Table 6 were removed prior to data analysis, as they were considered extreme outliers with z-scores greater than +/- 3.29 (Tabachnick \& Fidell, 2007).

Table 6

Cases with data contributing to outliers

\begin{tabular}{lccccc}
\hline Variable & Case \# & Z Score & Actual Value & Next Highest & Action \\
\hline Community & 17 & -3.42 & 1 & 1.29 & Removed \\
Community & 179 & -3.42 & 1 & 1.29 & Removed \\
Perform & 191 & -3.54 & 1 & 1.33 & Removed \\
Perform & 346 & -3.54 & 1 & 1.33 & Removed \\
Community & 346 & -3.42 & 1 & 1.29 & Removed \\
\hline
\end{tabular}


Next, variables were examined for approximate normal distribution. Histograms and Q-Q plots were examined, and skewness and kurtosis were calculated for each variable to confirm assumptions of normality. Skewness in absolute values was considered high if greater than 1 , moderate if between 1 and 0.5 , and fairly symmetrical between 0 and 0.5 (Bulmer 1979). Another suggested acceptable range for skewness and kurtosis was within $+/-1.5$ (Tabachnick \& Fidell, 2013). As shown in the Table 7, the skewness of the distribution was considered moderately skewed for workplace spirituality (-.559) and ethical leadership (-.890), and fairly symmetric for work intentions (-.265) based on Bulmer's (1979) criteria. Both skewness and kurtosis were within the $+/-1.5$ as by Tabachnick and Fidell (2013). Additionally, the examined histograms and Q-Q plots followed a linear pattern, and suggested that the data were normally distributed.

Table 7

Skewness and Kurtosis of Variables

\begin{tabular}{lcc}
\hline \multicolumn{1}{c}{ Variable } & Skewness & Kurtosis \\
\hline Workplace Spirituality & -.559 & -.088 \\
Work Intentions & -.265 & .488 \\
Ethical Leadership & -.890 & .160 \\
\hline
\end{tabular}

This study utilized a linear model and thus linearity was assumed. A visual evaluation of the histogram and P-P plot suggested that the model structure was normal and linear. As suggested by Field (2009), P-P plots provide a complementary visual evaluation of normal distribution, and based on the visual evaluation, normality of distribution and linearity may be assumed. Homoscedasticity was evaluated via the Durbin-Watson test, which showed a value of 1.87 for the dependent variable of work intentions, and 2.05 for ethical leadership. According to Field (2009), values less than 1 
or greater than 3 would be cause for concern. Homoscedasticity was also tested visually observing residuals via bivariate scatterplot shown below in Figure 2, and examined for an oval shape versus a cone or funnel shape (Green, 1991). The scatterplot showed a generally oval shape, and both the visual and numerical indicators suggest homogeneity and independence of errors.
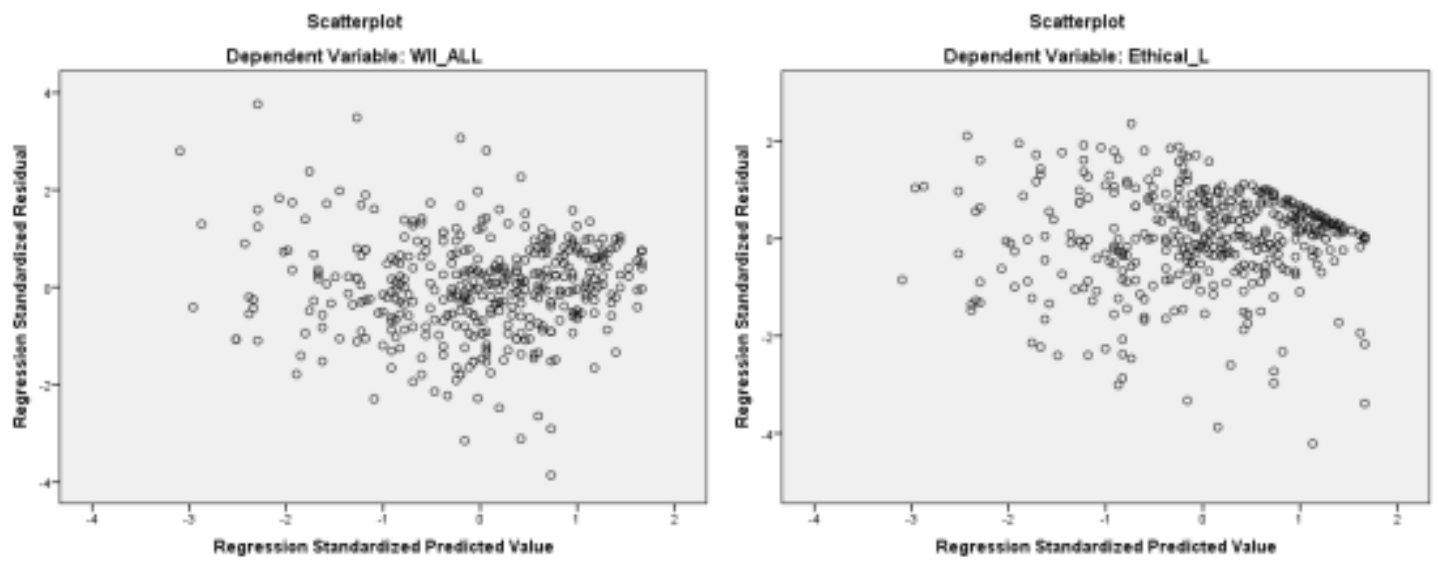

Figure 2. Residual data scatterplot

\section{Correlation analysis}

Pearson Product-Moment correlation coefficients were used to address RQ 1.

Specifically, correlations were computed among the eight subscales on data for 405 participants to determine the relationship between workplace spirituality and employees' intent to stay, perform, endorse, exert discretionary effort, and engage in OCB. The effect size for the correlations followed Cohen's (1988) criteria: $\geq .10=$ small; $\geq .30=$ moderate; and $\geq .50=$ strong

Table 8 reports the Pearson Product-Moment correlations. As shown, meaningful work was positively correlated with employees reported work intentions to endorse ( $r=$ $.63, p<.01)$, stay $(r=.63, p<.01)$, exert discretionary effort $(r=.52, p<.01)$, engage in OCB $(r=.45, p<.01)$, and perform $(r=.44, p<.01)$. Sense of community showed 
positive correlations with employees' intentions to endorse the organization $(r=.69, p<$ $.01)$, stay $(r=.64, p<.01)$, engage in OCB $(r=.55, p<.01)$, exert discretionary effort $(r$ $=.48, p<.01)$, and perform $(r=.47, p<.01)$. The dimension of alignment with organization values presented positive correlations with employees' reported intentions to endorse the organization $(r=.79, p<.01)$, stay $(r=.68, p<.01)$, engage in OCB $(r=$ $.55, p<.01)$, exert discretionary effort $(r=.53, p<.01)$, and to perform $(r=.41, p<.01)$.

Table 8

Subscale Level Correlations between Workplace Spirituality and Work Intentions

\begin{tabular}{lccccccc}
\hline & 1 & 2 & 3 & 4 & 5 & 6 & 7 \\
\hline (1) Meaning & - & & & & & & \\
(2) Community & $.664^{* *}$ & - & & & & & \\
(3) Values & $.648^{* *}$ & $.743^{* *}$ & - & & & & \\
(4) Effort & $.524^{* *}$ & $.482^{* *}$ & $.529^{* *}$ & - & & & \\
(5) Perform & $.442^{* *}$ & $.476^{* *}$ & $.415^{* *}$ & $.452^{* *}$ & - & & \\
(6) Endorse & $.629^{* *}$ & $.693^{* *}$ & $.793^{* *}$ & $.651^{* *}$ & $.582^{* *}$ & - & \\
(7) OCB & $.450^{* *}$ & $.549^{* *}$ & $.547^{* *}$ & $.465^{* *}$ & $.706^{* *}$ & $.662^{* *}$ & - \\
(8) Stay & $.627^{* *}$ & $.639^{* *}$ & $.678^{* *}$ & $.562^{* *}$ & $.489^{* *}$ & $.753^{* *}$ & $.547^{* *}$ \\
\hline
\end{tabular}

Note: $N=405$

*Correlation is significant at the .05 level.

${ }^{* *}$ Correlation is significant at the .01 level.

Overall, intent to endorse and intent to stay reported the strongest correlations with all three dimensions of workplace spirituality. Intent to engage in OCB and exert discretionary effort ranged between moderate and strong, and intent to perform, while showing moderate correlations ranging between .41 and .47 , consistently had the lowest correlation with all three dimensions of workplace spirituality. Results suggested moderate to strong positive relationships between workplace spirituality and work intentions. Respondents who scored highly on the workplace spirituality subscales also reported higher work intentions. In summary, the variables of interest showed significant 
associations, thus, these data supported the hypothesis of workplace spirituality's predictive relationship with work intentions.

\section{Path analysis}

Path analysis was used to test the hypothesized model depicted in Figure 3. Key model parameters of focus included: indirect effect of workplace spirituality on work intentions, and the degree to which ethical leadership mediated relationship between workplace spirituality and work intentions. The hypothesized path model was tested via using AMOS 24.0 (Arbuckle, 2016). The model was found to be acceptable: $\chi^{2}(2)=$ $.712, p=.701$ with $2 d f, \chi^{2}$ to $d f$ ratio $=.356, \mathrm{CFI}=1.0$, and RMSEA $=0.00$. The expected cross-validation index value of 0.066 was smaller than the saturated model (.074) or independence model (1.698), which suggested that the hypothesized model is likely to cross-validate across similar-sized samples from the same population.

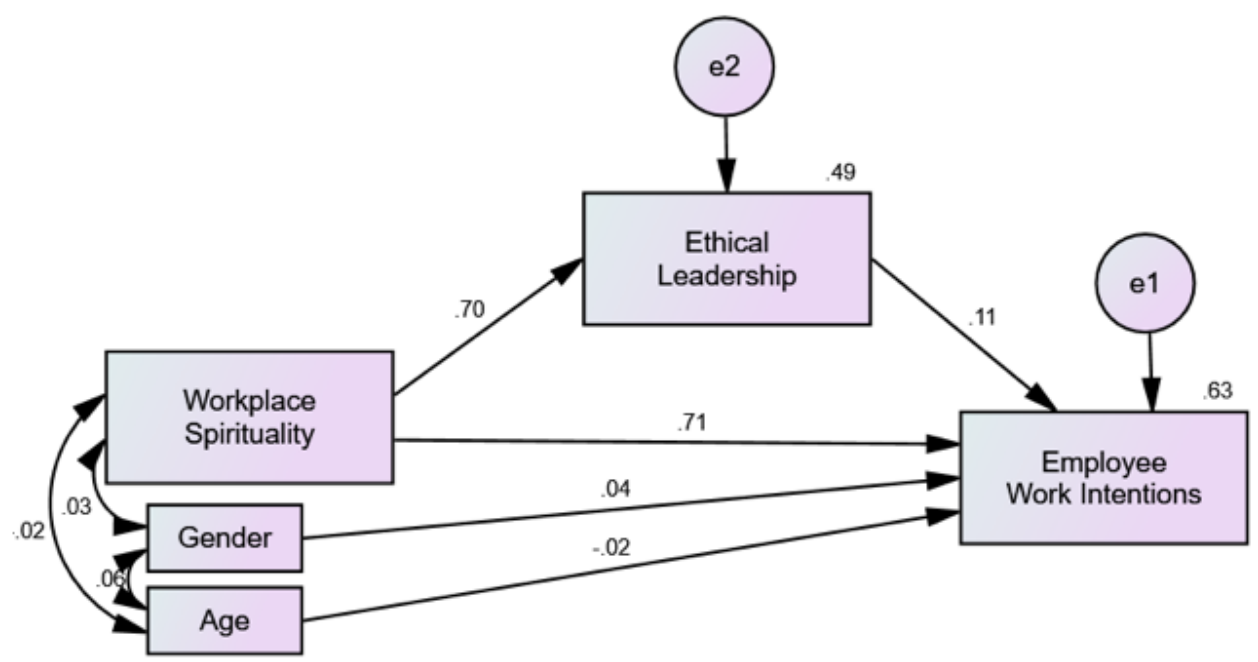

Figure 3. Path diagram for the hypothesized model

The mediating effect of ethical leadership on the relationship between workplace spirituality and employee work intentions was examined next. Path analysis using maximum likelihood estimation was conducted to test the proposed mediation model. As 
exhibited in Figure 3, there was a significant direct path from workplace spirituality to ethical leadership $(\beta=.70, p<.001)$, indicating that workplace spirituality was positively associated with the mediator variable of ethical leadership. Second, workplace spirituality also had a significant direct path to employee work intentions $(\beta=.71, p<.001)$, as expected. Third, the path coefficient from ethical leadership to work intentions $(\beta=.11, p$ $=.008)$ was statistically significant, indicating a positive association and represented a small effect. This model showed partial mediation, as all three path coefficients were statistically significant. The $R^{2}=.63$ indicated that $63 \%$ of the variance in work intentions was explained by the predictor variables. The indirect effect of workplace spirituality on work intentions via ethical leadership was statistically significant $(\beta=$ $.083, p=.011)$ as presented in Table 9 . The indirect effect indicated how much two cases that differ by one unit on workplace spirituality are estimated to differ on work intentions as a result of workplace spirituality's influence on ethical leadership which, in turn, affects work intentions.

Table 9

Direct and Indirect Effects

\begin{tabular}{lcccc}
\hline Estimated parameters & $\begin{array}{c}\text { Standardized } \\
\text { coefficients }\end{array}$ & $S E$ & $p$ & $\begin{array}{c}\text { BC95\%CI } \\
\text { lower/upper }\end{array}$ \\
\hline Direct effects & .697 & .046 & $<.001$ & \\
WS $\rightarrow$ EL & .710 & .044 & $<.001$ & \\
WS $\rightarrow$ work intentions & .040 & .076 & .189 & \\
Gender $\rightarrow$ work intentions & -.023 & .032 & .443 & \\
Age $\rightarrow$ work intentions & .112 & .035 & .008 & \\
EL $\rightarrow$ work intentions & & & & \\
Indirect Effects & .083 & .035 & .011 & $.019 / .164$ \\
WS $\rightarrow$ EL $\rightarrow$ work intentions &
\end{tabular}

Note: WS = workplace spirituality; EL = ethical leadership

Moreover, the direct effect of workplace spirituality on work intentions was tested 
in a model without mediation and resulted a significant path of $\beta=0.788$, which decreased to $\beta=0.710$ in the mediated model. The population value of the indirect effect for $A B$ with $95 \%$ bias-corrected confidence interval was between 0.019 and 0.164 . As this confidence interval does not straddle zero, it served as evidence that the indirect effect was positive to a statistically significant degree, and provided statistical evidence that ethical leadership mediated the positive effects of workplace spirituality on work intentions. The standardized coefficient estimate of .083 had a $p$ value of 0.011 , significantly different from zero at the 0.05 level.

\section{Summary}

This study sought to test a model on the relationship between workplace spirituality and work intentions, as well as determine if ethical leadership served as a mediator for that relation. The results of this study provided evidence towards the theoretical assumption that workplace spirituality and work intentions were related. Additionally, the path analysis showed a significant indirect effect of workplace spirituality on work intentions via ethical leadership. The results supported both hypotheses and confirmed a positive association between workplace spirituality and employee work intentions, and mediation via ethical leadership. 


\section{CHAPTER V \\ DISCUSSION AND CONCLUSIONS \\ Introduction}

The purpose of this study was to examine the relationship between workplace spirituality and employee work intentions. Specifically, this study set out to assess whether three dimensions of workplace spirituality (i.e., sense of community, meaningful work, and alignment with organizational values) were associated with five dimensions of employee work intentions (i.e., intent to stay, perform, exert discretionary effort, engage in $\mathrm{OCB}$, and endorse the organization). Moreover, this study set out determine whether ethical leadership mediated the relationship between workplace spirituality and employee work intentions. To expand the understanding of the contributions of workplace spirituality in the development of positive organizational cultures, this study expanded the growing body of research by contributing evidence towards the following two research questions:

1. To what extent, if any, does a relationship exist between the predictor variable of workplace spirituality and the criterion variable of employee w ork intentions?

2. Does ethical leadership mediate the relationship between workplace spirituality and employee work intentions?

\section{Summary of the Study}

Workplace spirituality has become increasingly more prominent and received considerable attention in scholarship and practice over the past two decades (Duchon \& 
Plowman, 2005; Giacalone \& Jurkiewicz, 2010). As an emerging theme in contemporary literature (Ashmos \& Duchon, 2000; Giacalone \& Jurkiewicz, 2003; Stevens, 2008), workplace spirituality has been broadly defined as an organization's recognition that employees have an inner life that nourishes and is nourished by meaningful work, and that takes place in the context of a community (Ashmos \& Duchon, 2000). Previous research reported that workplace spirituality was associated with positive benefits for both employees and organizations. On the organization side, workplace spirituality showed positive outcomes related to productivity (Sass, 2000), profits and morale (Benefiel, 2003), retention and commitment to the organizational vision (Duchon \& Plowman, 2005; Karakas, 2010), customer experience (Pandey et al., 2009), ethical values (Pawar, 2009), productive cultures (Giacalone \& Jurkiewicz, 2010), and job performance and employee attitudes (Jurkiewicz \& Giacalone, 2004; Milliman, et al, 2003). For employees, reported benefits included increased joy, peace, serenity, and job satisfaction (Giacalone \& Jurkiewicz, 2010); enhanced creativity, honesty, trust, personal fulfillment, and commitment (Krishnakumar \& Neck, 2002); and reduced friction and frustration at work (Kolodinsky et al., 2008).

As employees spend most of their waking hours and greatest effort in the workplace, their work and work environment becomes integral to their self-concept and quality of their lives outside of work (Giacalone \& Jurkiewicz, 2010). Scholars suggested that designing a work environment where employees have the opportunity to experience meaning and purpose in their work, sense of community through positive relationships, and alignment of personal and organizational values may be one of the most important managerial tasks of the twenty-first century (Milliman et al, 2003; Nichols, 1994; Porter 
\& Norris, 2012). The extant research findings supported Mitroff and Denton's (1999) initial assessment of workplace spirituality as a competitive advantage for organizations.

\section{Discussion of Results}

The dimensions of workplace spirituality and work intentions were suggested to be related in the literature (Fry \& Nisiewicz, 2013; Jurkiewicz \& Giacalone, 2004; Karakas, 2010; Krishnakumar \& Neck, 2002), yet no empirical evidence of their connection had been previously established. In this context, this study yields two key findings. First, the correlational analysis from this study's sample provided evidence toward this relation and theoretical assumption. Second, a path analysis showed that the mediated model explained $63 \%$ of the work intentions variance, and a significant indirect effect of workplace spirituality on work intentions via ethical leadership. By examining employees' self-reported experience of workplace spirituality, assessment of work intentions and ethical leadership, this study provided substantive understanding of the effects of higher levels of workplace spirituality and ethical leadership on work intentions. Grounded in previous theory and research, the following sections discuss the results of each hypothesis tested in this study. Results of this study suggested that there were statistically significant and meaningful relations to explore among the variables in this study.

\section{Hypothesis 1}

The first hypothesis stated that there would be a relation between the predictor variable of workplace spirituality and the criterion variable of work intentions. Results from the correlational analysis, following Cohen's (1988) effect size evaluation criterion $(\geq .10=$ small $; \geq .30=$ moderate; and $\geq .50=$ large $)$, indicated that there was in fact a 
significant positive relation between workplace spirituality and employee work intentions with a global scale correlation coefficient of $r=.79$. These findings provided evidence to support H1, and thus, the null hypothesis was rejected. The following sub-sections detail the results of each subscale of workplace spirituality and its relation to employee work intentions.

Alignment with organizational values indicated significant strong relations with employees' intent to endorse $(r=.79)$, stay $(r=.68)$, engage in OCB $(r=.55)$, exert discretionary effort $(r=.53)$ and a moderate relation with intent to perform $(r=.42)$. In line with previous studies, alignment with organizational values helped individuals feel that their work and lives were integrated, and thus, hours spent at work were more joyful, meaningful, and spiritually nourishing (Gibbons, 2007). Moreover, on a macro level, research has indicated that value alignment shapes a workforce that is more ethical and productive (Chalofsky, 2010).

Sense of community showed significant strong correlations with employee's intention to endorse $(r=.69)$, stay $(r=.64)$, engage in OCB $(r=.55)$ and moderate correlations with intent to exert discretionary effort $(r=.48)$, and perform $(r=.48)$. These findings are in line with previous research, which stated that sense of community fostered an environment of shared vision and responsibility, common values, boundaries, empowerment, growth and development, tension reduction, feedback, and friendship (Naylor et al, 1996). Additionally, this research paralleled previous findings suggesting that employees valued workplaces where they felt a part of a community (Miller, 1998; Pfeffer \& Veiga, 1999) and where they experienced a strong feeling of connectedness along with shared values and a sense of purpose (Chappell, 1993). 
Finally, meaningful work indicated large correlations with employee's intent to endorse $(r=.63)$, stay $(r=.63)$, exert discretionary effort $(r=.52)$ and moderate correlations with intent to engage in OCB $(r=.45)$, and perform $(r=.44)$. In line with previous research, meaning derived from work played an important role in workers' attitudes and behaviors (Duchon \& Plowman, 2005). Studies showed that employees who experienced meaningful work reported greater job satisfaction (Nord et al., 1990), placed a higher value on work (Harpaz \& Fu, 2002), and perceived work as more central and important (Arnold et al., 2007). Moreover, meaningful work was associated with greater employee well-being and personal growth, and captured the broader life context of people's work (Kamdron, 2005; Steger et al., 2012).

In summary, the results of the correlation analysis supported the first hypothesis regarding the relationship between workplace spirituality and employee work intentions. Overall, intent to endorse and intent to stay reported the strongest associations with all three dimensions of workplace spirituality. Intent to engage in OCB and exert discretionary effort ranged between moderate and strong, and intent to perform, while moderate, consistently had the lowest correlation with all three dimensions of w orkplace spirituality. The examination of job experiences stemming from workplace spirituality and its relation with employee work intentions provide opportunities for extending this research model by investigating the rate of which expressed intentions translate into actual behaviors, which will be addressed in the implications for research section.

\section{Hypothesis 2}

The second hypothesis stated that ethical leadership would mediate the relationship between workplace spirituality and employee work intentions. Evidence 
from the path analysis revealed that in the model mediated by ethical leadership, workplace spirituality explained $63 \%$ of the variance in employee work intentions. The $95 \%$ confidence interval of the indirect effect of workplace spirituality on work intentions through ethical leadership's mediation was estimated between $1.9 \%$ and $16.4 \%$. The direct effect of workplace spirituality on ethical leadership resulted in a path coefficient of $\beta=.70$, and ethical leadership's direct effect on employee work intentions was $\beta=.11$. As the standardized path coefficient from ethical leadership to work intentions was positive, it was presumed that employees who rated their leaders higher on ethical leadership were also likely to report higher work intentions.

As supported in previous research, the association between workplace spirituality and ethics suggested that the degree of individual spirituality influenced whether an individual perceives questionable business practice as ethical or unethical (Giacalone \& Jurkiewicz, 2003). Moreover, spirituality was found to be a determinant factor in a person's understanding and interpretation of ethical behavior, as many spiritual practices draw on prominent ethical theories and moral principles (Garcia-Zamor, 2003). The mediation of ethical leadership in the association between workplace spirituality and work intentions had not been previously investigated, however, previous research indicated that workplace spirituality was found to be related to ethical mindsets (Issa \& Pick, 2010) and the potential for ethical behavior (Beekun \& Westerman, 2012). This study indicated that, although employees may experience high levels of workplace spirituality, ethical leadership serves as an intermediate variable in cultivating positive work intentions.

Further investigation of the association between workplace spirituality and work 
intentions, and how a leader's ethical behavior influences employees' experience in the workplace is worthy of further inquiry. Ethical leadership is uniquely significant because of the impact leaders may have on the conduct of others within the organization and ultimately, organizational performance (Aronson, 2001; Kanungo, 2001; Trevino, Brown, \& Hartman, 2003). Moreover, previous findings reported that leaders who treated their employees fairly elicited $\mathrm{OCB}$, and indicated that ethical leadership was related with perceived employee effectiveness (Kalshoven, Den Hartog, \& De Hoogh, 2011).The social learning theory (Bandura, 1977, 1986), established that followers come to behave similarly to their leaders through imitation and observational learning, (Brown et al. 2005) and as such, if the leader treats employees fairly and respectfully, employees, in turn, become more likely to treat others in such a manner (Sama \& Shoaf, 2008). Similarly, the social exchange theory (Blau, 1964) focuses on the norm for reciprocity (Cropanzano \& Mitchell, 2005), suggesting that employees tend to reciprocate fair treatment (Mayer et al., 2009; Eddy \& VanDerLinden, 2006).

Overall, workplace spirituality, ethical leadership and work intentions are positioned to be valuable contributors to organizations, in terms of positive organizational cultures, employee's experience of meaningful work and sense of community, satisfaction, and performance. The findings of this study showed general support for both hypotheses and confirmed a positive association between workplace spirituality and employee work intentions, and mediation via ethical leadership. By expanding the understanding of the relationship between these variables, an important contribution lies in advancing the literature of workplace spirituality by demonstrating its positive effects, and promoting avenues for the integration of workplace spirituality and ethical leadership 
into organizational cultures.

\section{Implications for Theory, Research and Practice}

In light of the findings of this study, implications for theory, research and practice were considered. The three variables in this study, workplace spirituality, ethical leadership and work intentions crossed paths throughout the documented literature, yet had not been extensively evaluated together prior to this work.

\section{Implications for Theory}

Workplace spirituality theory was built on the premise of organizational recognition that employees have an inner life that is nourished by meaningful work and takes place in the context of their work community (Ashmos \& Duchon, 2000). To date, research associated with workplace spirituality showed numerous positive benefits at the organizational and employee level. The findings of this study serve as important indicators for organizations to assess employee's experience in the workplace and how it influences employee intentionality to perform positive work behaviors. Theory and research have previously shown a connection between appraisal, intentionality, and behavior (Ajzen \& Fishbein, 1980; Bagozzi, 1992). This study contributed to workplace spirituality theory by uncovering its influence on work intentions via an appraisal of the contextual work environment related to the experiences of meaningful work, sense of community, and alignment with organizational values.

The relationship between workplace spirituality and ethical leadership had been substantiated in theory (Brown \& Treviño, 2006; Corner, 2009; Giacalone \& Jurkiewicz 2003; Issa \& Pick, 2010), however empirical studies thus far have been limited and mostly examined through the lenses of work values, exemplified by qualities such as 
benevolence (Adams, Balfour, \& Reed, 2006), integrity (George, Ellison, \& Larson, 2002; Kouzes \& Posner 1995), justice, utilitarianism, and relativism (Beekun \& Westerman, 2012). Nonetheless, the relationship between workplace spirituality and ethical leadership remains woefully underexplored. This study's contributions to the theoretical understanding of workplace spirituality, perceptions of ethical leadership, and work intentions as indicators of employee's experience in the workplace can guide organizations in evaluating the state of their workforce. Likewise, the results from this study could be used to understand the interplay of these three variables. Further, results from this study directly extend the theoretical development and contextual understanding of workplace spirituality and its place in organizational research. Additional empirical investigation on the relationship between these constructs would be beneficial and would add to the development of the workplace spirituality theory.

\section{Implications for Research}

The correlation analysis supported the hypothesized relationship between workplace spirituality and employee work intentions. The examination of job experiences stemming from workplace spirituality and its relation with employee work intentions provides opportunities to extend this research model by integrating intended and actual behaviors. The findings of this exploratory study set the foundation for future research, where the next stage would be a more complex two stage model that assesses employees' work intentions and actual behaviors. This would provide information regarding the rate of which employees follow through on expressed intentions. This theoretical model originated from similar research which examined intended and actual turnover (Vardaman, Taylor, Allen, Gondo, \& Amis, 2015). 
Another important implication for research resulting from this study relates to the sample, which was comprised of individuals employed full time in the United States. This sample was less specific than managers and technical professionals (Giacalone \& Jurkiewicz, 2003), or health, community services and education professionals (Issa \& Pick, 2011). Future research might consider industry specific settings, such as healthcare, education, and/or retail to tease out any nuanced, labor-specific differences. Additionally, as spirituality is considered a cultural fact (Shafranske \& Malony, 1996), future research should explore cultural variances such as power distance, uncertainty avoidance, and/or individualism versus collectivism (Hofstede, 1983). Collectivistic cultures, for example, promote a sense of self as embedded within a network of social ties whereas individualistic cultures promote a sense of self as independent (Markus \& Kitayama, 1991). The manifestations of spirituality through the lenses of different cultures, particularly in the context of national cultures, could reveal aspects of workplace spirituality relevant to international HRD, providing additional information in terms of inclusivity and understanding a global workforce.

Future research should also consider virtual teams and telecommuting. As of 2010, the BLS estimated that approximately $17 \%$ of the US workforce primarily works from home (U.S. Bureau of Labor Statistics, 2010). Virtual teams, in turn, could provide information from a global perspective, including cultural variations. Additionally, future research would also benefit from understanding the relationship of workplace spirituality and other variables empirically connected to employee behavior such as employee engagement, absenteeism, turnover, deviant workplace behavior, and job satisfaction. Evaluating employee experience through these lenses would uncover valuable data 
regarding workplace spirituality and its influence on employee work intentions and organizational outcomes.

\section{Implications for Practice}

Workplace spirituality research showed that employees who can bring their whole self to work exhibited greater ethical behavior (Beekun \& Westerman, 2012), experienced improved job satisfaction (Giacalone \& Jurkiewicz, 2010), enhanced personal fulfillment (Krishnakumar \& Neck, 2002), and reduced friction and frustration at work (Kolodinsky et al., 2008). The positive association between workplace spirituality and work intentions showed great potential to further understand the benefits workplace spirituality brings to organizations and employees. An organization that desires to foster workplace spirituality by supporting the experience of meaningful work, sense of community and alignment with organizational values can evaluate the services it provides as an organization and then explore how each position, functional area or department contributes to the mission of the organization, and how these contributions are aligned with the values the organization desires to uphold. Internally identifying service provider, customers, stakeholders and beneficiaries of each department or function would allow employees to visualize how their work fits in and contributes to the overall organizational mission.

A pre-assessment using the scales from this study can be utilized at the onset, with a reassessment after 12 months. During the 12-month period, employees should be provided with training and development to better understand organizational values and express them in everyday work and interactions. The results of the pre-assessment will provide guiding information for organizational leaders to focus on developing the 
organizational strategy within the 1-year period. If for example, sense of community is rated low, the organization can focus on how to improve the experience of sense of community among its employees. To promote meaningful work, an organization may tap into its vision, contributions and overall outcomes achieved, and enable organizational leaders to help employees recognize the meaning of their work. Helping employees make the connection from what they contribute individually to what the organization accomplishes as a whole can help employees derive meaning from their work and connect it to the greater purpose of their lives. Results from this study suggest that doing so would be related to a myriad of important organizationally focused outcomes.

Workplace spirituality through the lens of alignment with organizational values suggests that ethical leaders may stimulate ethicality among subordinates. One of the basic tenets of the employment relationship is grounded on the traditional master/servant relationship, known as the law of agency. The law of agency states that the employer is responsible for the actions of its employees (Linder, 1989); therefore, if employees make false claims or engages in inappropriate, unethical behavior in the workplace, the employer is ultimately responsible for the harm incurred. As a recommendation for practice, organizations should be clear regarding employment policies in terms of the organizational values, ethical standards, and expectations. As an opportunity for training and development, this process can begin during the onboarding process to allow newhires to recognize whether their personal values align with the values of the organization. Training on ethical standards enables employees to recognize on behalf of the organization when organizational values are not being upheld through the course of business conduct. Additionally, provisions and policies that protect employees who report 
wrongdoing in good faith must be in place and followed. Since this study considered the ethicality of leaders, we also must consider scenarios where ethical leadership is lacking, making a possible way for dysfunctional leadership (Rose, Shuck, Twyford, \& Bergman, 2015) and workplace deviance (Robinson \& Bennett, 1995), which are detrimental to employee's workplace experience and organizational performance.

Human resources practitioners and organizational leaders can foster through workplace spirituality benefits such as increased employee well-being, morale, commitment, and productivity, and reduced stress and burnout (Karakas, 2010). Developing a sense of connectedness and community promotes employee loyalty, and feeling of belonging to the organization. Workplace spirituality is focused on employee well-being and the quality of the workplace experience. The obsession with organizational performance and return on investment prevents organizations from realizing the positive effects resulting from workplace spirituality. Workplace spirituality has the capacity to translate into better organizational performance; however, it would be misleading of organizations to pursue it with the sole purpose of enhancing the bottom line. As suggested by Dehler and Welsh (2010), this approach would fail because talent and knowledge would walk out the door in search of meaning. The organizational philosophy in terms of workplace spirituality realizes that the benefits are beyond short term and bottom line outcomes.

Additionally, workplace spirituality resonates with recently emerging corporate social responsibility programs, characterized by the actions of a firm that benefit society beyond the requirements of the law and the direct interests of the firm (Lane \& Maznevski, 2014). Pressure for greater attention to social responsibility has emanated 
from a range of stakeholders, as organizations are urged to be more responsive to the range of social needs in their communities and workforce, including concerns about working conditions and environmental impact of their activities. This alignment of company's activities with societal interest can lend itself to the organizational relationships with its employees. Finally, the scientific study of spirituality, long taboo in the social sciences (Emmons, 2003), is beginning to open up new views for greater understanding of individuals in the workplace beyond concerns of productivity, performance, or the size of the paycheck. 


\section{REFERENCES}

Academy of Management. (2015). Management spirituality and religion. Retrieved from http://aom.org/Divisions-and-Interest-Groups/Management-Spirituality-andReligion/Management-Spirituality-and-Religion.aspx

Adams, D. W., \& Csiernik, R. (2002). Seeking the lost spirit: Understanding spirituality and restoring it to the workplace. Employee Assistance Quarterly, 17(4), 31-44. http://dx.doi.org/10.1300/J022v17n04_03

Adams, G. B., Balfour, D. L., \& Reed, G. E. (2006). Abu Ghraib, administrative evil, and moral inversion: The value of "Putting Cruelty First". Public Administration Review, 66(5), 680-693. http://dx.doi.org/10.1111/j.1540-6210.2006.00633.x

Ajzen, I. (1985). From intentions to actions: A theory of planned behavior. In J. Kuhl \& J. Beckmann (Eds.), Action-control: From cognition to behavior (pp. 11-39). New York, NY: Springer.

Ajzen, I. (1991). The theory of planned behavior. Organizational Behavior and Human Decision Processes, 50, 179-211. http://dx.doi.org/10.1016/07495978(91)90020T

Ajzen, I., Albarracin, D., \& Hornik, R. (2007). Prediction and Change of Health Behavior: Applying the Reasoned Action Approach. Mahwah, NJ: Lawrence Erlbaum Associates.

Ajzen, I., \& Fishbein, M. (1980). Understanding attitudes and predicting social behavior. Upper Saddle River, NJ: Prentice Hall. 
Alagaraja, M., \& Shuck, B. (2015). Exploring organizational alignment-employee engagement linkages and impact on individual performance: A conceptual model. Human Resource Development Review, 14(1), 17-37. http://dx.doi.org/10.1177/1534484314549455

Andersson, L. M., \& Bateman, T. S. (1997). Cynicism in the workplace: Some causes and effects. Journal of Organizational Behavior, 18, 449-469. http://dx.doi.org/10.1002/(SICI)1099-1379(199709)18:5\%3C449::AIDJOB808\%3E3.0.CO;2-O

Arbuckle, James L. (2016), IBM ${ }^{\circledR}$ SPSS ${ }^{\circledR}$ Amos $^{\mathrm{TM}} 24$ User’s guide. Chicago, IL: Amos Development Corporation

Ardichvili, A., Mitchell, J. A., \& Jondle, D. (2009). Characteristics of ethical business cultures. Journal of Business Ethics, 85, 445-451. http://dx.doi.org/10.1007/ s10551-008-9782-4

Arnold, K. A., Turner, N., Barling, J., Kelloway, E. K., \& McKee, M. C. (2007). Transformational leadership and psychological well-being: The mediating role of meaningful work. Journal of Occupational Health Psychology, 12, 193-203. http://dx.doi.org/10.1037/1076-8998.12.3.193

Aronson, E. (2001). Integrating leadership styles and ethical perspectives. Canadian Journal of Administrative Sciences/Revue Canadienne des Sciences de l'Administration, 18(4), 244-256. http://dx.doi.org/10.1111/j.19364490.2001.tb00260.x 
Ashar, H., \& Lane-Maher, M. (2004). Success and spirituality in the new business paradigm. Journal of Management Inquiry, 13, 249-260. http://dx.doi.org/ $10.1177 / 1056492604268218$

Ashmos, D., \& Duchon, D. (2000). Spirituality at work: A conceptualization and measure. Journal of Management Inquiry, 9, 134-145. http://dx.doi.org/ $10.1177 / 105649260092008$

Avolio, B. J., \& Gardner, W. L. (2005). Authentic leadership development: Getting to the root of positive forms of leadership. The Leadership Quarterly, 16, 315-338. http://dx.doi.org/10.1016/j.leaqua.2005.03.001

Bagozzi, R. P. (1992). The self-regulation of attitudes, intentions, and behavior. Social Psychology Quarterly, 55, 178-204. http://dx.doi.org/10.2307/2786945

Baker, R., Brick, J. M., Bates, N. A., Battaglia, M., Couper, M. P., Dever, J. A., . . . Tourangeau, R. (2013). Summary report of the AAPOR Task Force on NonProbability Sampling. Journal of Survey Statistics and Methodology, 1, 90-143. http://dx.doi.org/10.1093/jssam/smt00

Bandura, A. (1977). Self-efficacy: toward a unifying theory of behavioral change. Psychological review, 84(2), 191. http://dx.doi.org/10.1037/0033-295X.84.2.191

Bandura, A. (1986). Social foundations of thought and action: A social cognitive theory: Prentice-Hall, Inc.

Bateman, T. S., \& Organ, D. W. (1983). Job satisfaction and the good soldier: The relationship between affect and employee "citizenship". Academy of Management Journal, 26, 587-595. http://dx.doi.org/10.2307/255908 
Beekun, R. I., \& Westerman, J. W. (2012). Spirituality and national culture as antecedents to ethical decision-making: A comparison between the United States and Norway. Journal of Business Ethics, 110, 33-44. http://dx.doi.org/10.1007/s10551-011-1145-x

Bell, E., \& Taylor, S. (2004). From outward bound to inward bound': the prophetic voices and discursive practices of spiritual management development. Human Relations, 57(4), 439-466. http://dx.doi.org/10.1177/0018726704043895

Benefiel, M. (2003). Irreconcilable foes? The discourse of spirituality and the discourse of organizational science. Organization, 10(2), 383-391. http://dx.doi.org/10.1177/1350508403010002012

Blair, E., \& Zinkhan, G. M. (2006). Nonresponse and generalizability in academic research. Journal of the Academy of Marketing Science, 34, 4-7. http://dx.doi.org/ $10.1177 / 0092070305283778$

Blau, P. (1964). Power and exchange in social life. New York: J Wiley \& Sons, 352.

Boje, D. (2008). Critical Theory approaches to spirituality in business Spirituality in Business (pp. 160-187): Springer. http://dx.doi.org/10.1057/9780230611887_10

Bornstein, M. H., Jager, J., \& Putnick, D. L. (2013). Sampling in developmental science: Situations, shortcomings, solutions, and standards. Developmental Review, 33, 357-370. http://dx.doi.org/10.1016/j.dr.2013.08.003

Bowen, M. G., Ferris, G. R., \& Kolodinsky, R. (2010). Political skill, servant leadership, and workplace spirituality in the creation of effective work environments. In R. A. Giacalone \& C. L. Jurkiewicz (Eds.), The handbook of workplace spirituality and 
organizational performance (2nd ed., pp. 126-142). New York, NY: M. E. Sharpe.

Brandon, D. M., Long, J. H., Loraas, T. M., Mueller-Phillips, J., \& Vansant, B. (2013). Online instrument delivery and participant recruitment services: Emerging opportunities for behavioral accounting research. Behavioral Research in Accounting, 26(1), 1-23. http://dx.doi.org/10.2308/bria-50651

Branson, C. M. (2008). Achieving organisational change through values alignment. Journal of Educational Administration, 46(3), 376-395. http://dx.doi.org/ $10.1108 / 09578230810869293$

Briskin, A. (1998). The stirring of the soul in the workplace. San Francisco, CA: BerrettKoehler Publishers.

Brown, M. E., \& Treviño, L. K. (2006). Ethical leadership: A review and future directions. The Leadership Quarterly, 17, 595-616. http://dx.doi.org/10.1016/ j.leaqua.2006.10.004

Brown, M. E., Treviño, L. K., \& Harrison, D. A. (2005). Ethical leadership: A social learning perspective for construct development and testing. Organizational Behavior and Human Decision Processes, 97(2), 117-134. http://dx.doi.org/ 10.1016/j.obhdp.2005.03.002

Bulmer, M. G. (1979). Principles of Statistics Dover Publications. New York.

Callahan, J. L., \& Ward, D. B. (2001). A search for meaning: revitalizing the 'human' in human resource development. Human Resource Development International, 4, 235-242. http://dx.doi.org/10.1080/13678860122471 
Capra, F. (1996). The web of life: A new scientific understanding of living systems. New York, NY: Random House.

Cavanagh, G. F. (1999). Spirituality for managers: Context and critique. Journal of Organizational Change Management, 12, 186-199. http://dx.doi.org/10.1108/ 09534819910273793

Chalofsky, N. (2000). The meaning of the meaning of work: A literature review analysis. In K. P. Kuchinke (Ed.), Academy of Human Resource Development Conference Proceedings (Vol. 1, pp. 94-100). Baton Rouge, LA: AHRD.

Chalofsky, N. (2010). Meaningful Workplaces: Integrating the Individual and the Organization: Hoboken, NJ, USA: Jossey-Bass.

Chappell, T. (1993). The soul of a business: Managing for profit and the common good. New York, NY: Bantam Books.

Chen, Z. X., Aryee, S., \& Lee, C. (2005). Test of a mediation model of perceived organizational support. Journal of Vocational Behavior, 66, 457-470. http://dx.doi.org/10.1016/j.jvb.2004.01.001

Ciulla, J. B. (2014). Ethics, the heart of leadership (3rd ed.). Santa Barbara, CA: Praeger. Cohen, J., Cohen, P., West, S. G., \& Aiken, L. S. (1983). Multiple regression/correlation analysis for the behavioral sciences. Hillsdale, NJ: Earlbaum.

Cohen, J. (1988). Statistical Power Analysis for the Behavioral Sciences. Hillsdale, N.J.: L. Erlbaum Associates.

Colquitt, J. A., Conlon, D. E., Wesson, M. J., Porter, C. O. L. H., \& Ng, K. Y. (2001). Justice at the millennium: A meta-analytic review of 25 years of organizational 
justice research. Journal of Applied Psychology, 86, 425-445. http://dx.doi.org/ 10.1037/0021-9010.86.3.425

Cook, T. D., \& Campbell, D. T. (1979). Quasi-experimentation: Design and analysis for field settings. Boston: Houghton Mifflin.

Corner, P. D. (2009). Workplace spirituality and business ethics: Insights from an Eastern spiritual tradition. Journal of Business Ethics, 85, 377-389. http://dx.doi.org/ $10.1007 / \mathrm{s} 10551-008-9776-2$

Creswell, J. W. (2012). Educational research: Planning, conducting, and evaluating quantitative and qualitative research (4th ed.). New York, NY: Pearson.

Cropanzano, R., \& Mitchell, M. S. (2005). Social exchange theory: An interdisciplinary review. Journal of Management, 31, 874-900. http://dx.doi.org/10.1177/ 0149206305279602

Dabke, D., \& Patole, S. (2014). Do Perceived Organizational Support, Perceived Superior Support, Goal Clarity, Perceived Career Progression Opportunities and Job Satisfaction predict Intention to Stay. International Journal of Research in Management \& Technology, 4(2), 114-126. Retrieved from http://www.iracst.org/ijrmt/vol4no2.htm

De Hoogh, A. H. B., \& Den Hartog, D. N. (2008). Ethical and despotic leadership, relationships with leader's social responsibility, top management team effectiveness and subordinates' optimism: A multi-method study. The Leadership Quarterly, 19, 297-311. http://dx.doi.org/10.1016/j.leaqua.2008.03.002 
Den Hartog, D., \& Belschak, F. (2012). Work engagement and Machiavellianism in the ethical leadership process. Journal of Business Ethics, 107(1), 35-47. http://dx.doi.org/10.1007/s10551-012-1296-4

De Klerk, J. J. (2005). Spirituality, meaning in life, and work wellness: A research agenda. International Journal of Organizational Analysis, 13, 64-68. http://dx.doi.org/10.1108/eb028998

Dehler, G. E., \& Welsh, M. A. (2010). The experience of work: Spirituality and the new workplace. In R. A. Giacalone \& C. L. Jurkiewicz (Eds.), Handbook of workplace spirituality and organizational performance (2nd ed., pp. 59-72). New York, NY: Routledge.

Delbecq, A. L. (2010). Foreword to the second edition. In R. A. Giacalone \& C. L. Jurkiewicz (Eds.), Handbook of workplace spirituality and organizational performance (pp. vii-x). New York, NY: M. E. Sharpe.

Dillman, D. A., Smyth, J. D., \& Christian, L. M. (2014). Internet, phone, mail, and mixed-mode surveys: The tailored design method (4th ed.). Hoboken, NJ: Wiley.

Douglas, P. C., Davidson, R. A., \& Schwartz, B. N. (2001). The effect of organizational culture and ethical orientation on accountants' ethical judgments. Journal of Business Ethics, 34, 101-121. http://dx.doi.org/10.1023/A:1012261900281

Duchon, D., \& Plowman, D. A. (2005). Nurturing the spirit at work: Impact on work unit performance. The Leadership Quarterly, 16, 807-833. http://dx.doi.org/10.1016/ j.leaqua.2005.07.008 
Eddy, P. L., \& VanDerLinden, K. E. (2006). Emerging definitions of leadership in higher education new visions of leadership or same old "hero" leader?. Community College Review, 34(1), 5-26. http://dx.doi.org/10.1177/0091552106289703

Elkins, D. N. (1995). Psychotherapy and spirituality: Toward a theory of the soul. Journal of Humanistic Psychology. http://dx.doi.org/10.1177/ 00221678950352006

Elliott, C., \& Turnbull, S. (Eds.). (2004). Critical thinking in human resource development. New York, NY: Routledge.

Emblen, J. D. (1992). Religion and spirituality defined according to current use in nursing literature. Journal of Professional Nursing, 8(1), 41-47. http://dx.doi.org/ 10.1016/8755-7223(92)90116-G

Emmons, R. A. (1999). The psychology of ultimate concerns: Motivation and spirituality in personality: Guilford Press.

Emmons, R. A. (2003). Personal goals, life meaning, and virtue: Wellsprings of a positive life. Flourishing: Positive psychology and the life well-lived, 105-128.

Fairholm, G. W. (2011). Real leadership: How spiritual values give leadership meaning. Santa Barbara, CA: Praeger.

Faul, F., Erdfelder, E., Buchner, A., \& Lang, A. (2009). Statistical power analyses using gpower 3.1: Tests for correlation and regression analyses. Behavior Research Methods, 41(4), 1149-1160. http://dx.doi.org/10.3758/BRM.41.4.1149

Field, A. (2009). Discovering statistics using SPSS: Sage publications. 
Firth, L., Mellor, D. J., Moore, K. A., \& Loquet, C. (2004). How can managers reduce employee intention to quit? Journal of Managerial Psychology, 19(2), 170-187. http://dx.doi.org/10.1108/02683940410526127

Fishbein, M., \& Ajzen, I. (1975). Belief, attitude, intention and behavior: An introduction to theory and research. Cambridge, MA: Addison-Wesley.

Fishbein, M., \& Ajzen, I. (2010). Predicting and changing behavior: The reasoned action approach. New York, NY: Psychology Press

Freiberg, K., \& Freiberg, J. (1996). Nuts!: Southwest Airlines' crazy recipe for business and personal success. Austin, TX: Bard Books

Fricker, R. D. (2008). Sampling methods for web and e-mail surveys. In N. G. Fielding, R. M. Lee, \& G. Blank, The Sage handbook of online research methods (pp. 195216). Thousand Oaks, CA: Sage.

Fry, L. W. (2003). Toward a theory of spiritual leadership. The Leadership Quarterly, 14, 693-727. http://dx.doi.org/10.1016/j.leaqua.2003.09.001

Fry, L. W. (2005). Toward a theory of ethical and spiritual well-being, and corporate social responsibility through spiritual leadership. In R. A. Giacalone, C. L. Jurkiewicz, \& C. Dunn (Eds.), Positive psychology in business ethics and corporate responsibility (pp. 47-83). Greenwich, CT: Information Age.

Fry, L. W., \& Nisiewicz, M. (2013). Maximizing the triple bottom line through spiritual leadership. Stanford, CA: Stanford University Press.

Gall, M. D., Borg, W. R., \& Gall, J. P. (1996). Educational research: An introduction (6th ed.). London, England: Longman. 
Garcia-Zamor, J. C. (2003). Workplace spirituality and organizational performance. Public administration review, 63(3), 355-363. http://dx.doi.org/10.1111/15406210.00295

Gardner, W. L., Avolio, B. J., Luthans, F., May, D. R., \& Walumbwa, F. (2005). “Can you see the real me?" A self-based model of authentic leader and follower development. The Leadership Quarterly, 16, 343-372. http://dx.doi.org/10.1016/ j.leaqua.2005.03.003

Garrett, L. E., Spreitzer, G. M., \& Bacevice, P. (2014, January). Co-constructing a sense of community at work: The emergence of community in coworking spaces. Academy of Management Proceedings, 2014(Suppl. 1), Art. No. 14004. http://dx.doi.org/10.5465/AMBPP.2014.139

Geigle, D. (2012). Workplace spirituality empirical research: A literature review. Business and Management Review, 2(10), 14-27. Retrieved from http://www.businessjournalz.org/

George, L. K., Ellison, C. G., \& Larson, D. B. (2002). Explaining the relationships between religious involvement and health. Psychological inquiry, 13(3), 190-200. http://dx.doi.org/10.1207/S15327965PLI1303_04

Giacalone, R. A., \& Eylon, D. (2000). The development of new paradigm values, thinkers, and business: Initial frameworks for a changing business worldview. American Behavioral Scientist, 43, 1217-1230. http://dx.doi.org/ 10.117700027640021955838

Giacalone, R. A., \& Jurkiewicz, C. L. (2003a). Handbook of workplace spirituality and organizational performance. New York, NY: M. E. Sharpe. 
Giacalone, R. A., \& Jurkiewicz, C. L. (2003b). Toward a science of workplace spirituality. In R. A. Giacalone \& C. L. Jurkiewicz (Eds.), Handbook of workplace spirituality and organizational performance (pp. 3-28). New York, NY: M. E. Sharpe.

Giacalone, R. A., \& Jurkiewicz, C. L. (2010). The science of workplace spirituality. In R. A. Giacalone \& C. L. Jurkiewicz (Eds.), Handbook of workplace spirituality and organizational performance (2nd ed., pp. 3-26). New York, NY: M. E. Sharpe.

Gibbons, P. (2001). Spirituality at work: A pre-theoretical overview. Articles on leadership.

Gibbons, P. (2000). Spirituality at work: Definitions, measures, assumptions, and validity claims. In J. Biberman \& M. D. Whitty (Eds.), Work and spirit: A reader of new spiritual paradigms for organizations (pp. 111-131). Scranton, PA: University of Scranton Press.

Gotsis, G., \& Kortezi, Z. (2008). Philosophical foundations of workplace spirituality: A critical approach. Journal of Business Ethics, 78, 575-600. http://dx.doi.org/10.1007/s10551-007-9369-5

Green, S. B. (1991). How many subjects does it take to do a regression analysis. Multivariate behavioral research, 26(3), 499-510. http://dx.doi.org/ $10.1207 / \mathrm{s} 15327906 \mathrm{mbr} 2603 \_7$

Gull, G. A., \& Doh, J. (2004). The "transmutation" of the organization: Toward a more spiritual workplace. Journal of Management Inquiry, 13(2), 128-139. http://dx.doi.org/10.1177/1056492604265218 
Gyatso, T. (1999). Ancient Wisdom, modern world: ethics for a New Millenium. Little, Brown.

Hackman, J. R., \& Oldham, G. R. (1976). Motivation through the design of work: Test of a theory. Organizational behavior and human performance, 16(2), 250-279. http://dx.doi.org/10.1016/0030-5073(76)90016-7

Harman, W. W., \& Hormann, J. (1990). Creative work: The constructive role of business in a transforming society. Indianapolis, IN: Knowledge Systems.

Harpaz, I., \& Fu, X. (2002). The structure of the meaning of work: A relative stability amidst change. Human Relations, 55, 639-667. http://dx.doi.org/10.1177/ 0018726702556002

Hassan, S., Mahsud, R., Yukl, G., \& Prussia, G. E. (2013). Ethical and empowering leadership and leader effectiveness. Journal of Managerial Psychology, 28, 133146. http://dx.doi.org/10.1108/02683941311300252

Hassan, S., Wright, B. E., \& Yukl, G. (2014). Does ethical leadership matter in government? Effects on organizational commitment, absenteeism, and willingness to report ethical problems. Public Administration Review, 74, 333-343. http://dx.doi.org/10.1111/puar.12216

Hayes, A. F. (2013). Introduction to mediation, moderation, and conditional process analysis: A regression-based approach: Guilford Press.

Henson, R. K. (2001). Understanding internal consistency reliability estimates: A conceptual primer on coefficient alpha. Measurement and evaluation in counseling and development, 34(3), 177. 
Hicks, D. A. (2003). Religion and the workplace: Pluralism, spirituality, leadership. New York, NY: Cambridge University Press.

Hofstede, G. (1983). National cultures in four dimensions: A research-based theory of cultural differences among nations. International Studies of Management \& Organization, 13(1-2), 46-74. http://dx.doi.org/10.1080/00208825.1983.11656358

Hu, L. T., \& Bentler, P. M. (1999). Cutoff criteria for fit indexes in covariance structure analysis: Conventional criteria versus new alternatives. Structural equation modeling: a multidisciplinary journal, 6(1), 1-55. http://dx.doi.org/ $10.1080 / 10705519909540118$

Huhtala, M., Feldt, T., Lämsä, A.-M., Mauno, S., \& Kinnunen, U. (2011). Does the ethical culture of organisations promote managers' occupational well-being? Investigating indirect links via ethical strain. Journal of Business Ethics, 101, 231-247. http://dx.doi.org/10.1007/s10551-010-0719-3

Issa, T., \& Pick, D. (2010). Ethical mindsets: An Australian study. Journal of Business Ethics, 96, 613-629. http://dx.doi.org/10.1007/s10551-010-0487-0

Judd CM, Kenny DA. (1981). Estimating the effects of social interventions. Cambridge University Press; Cambridge, England.

Jurkiewicz, C. L., \& Giacalone, R. A. (2004). A values framework for measuring the impact of workplace spirituality on organizational performance. Journal of Business Ethics, 49, 129-142. 10.1023/B:BUSI.0000015843.22195.b9

Kalshoven, K., Den Hartog, D. N., \& De Hoogh, A. H. (2011). Ethical leadership at work questionnaire (ELW): Development and validation of a multidimensional 
measure. The Leadership Quarterly, 22(1), 51-69. http://dx.doi.org/10.1016/ j.leaqua.2010.12.007

Kamdar, D., McAllister, D. J., \& Turban, D. B. (2006). "All in a day's work": How follower individual differences and justice perceptions predict OCB role definitions and behavior. Journal of Applied Psychology, 91, 841-855. http://dx.doi.org/10.1037/0021-9010.91.4.841

Kamdron, T. (2005). Work motivation and job satisfaction of Estonian higher officials. International Journal of Public Administration, 28, 1211-1240. http://dx.doi.org/ $10.1080 / 01900690500241085$

Kanungo, R. N. (2001). Ethical values of transactional and transformational leaders. Canadian Journal of Administrative Sciences/Revue Canadienne des Sciences de l'Administration, 18(4), 257-265. http://dx.doi.org/10.1111/j.19364490.2001.tb00261.x

Karakas, F. (2010). Spirituality and performance in organizations: A literature review. Journal of Business Ethics, 94, 89-106. http://dx.doi.org/10.1007/s10551-009$0251-5$

Kinjerski, V. M., \& Skrypnek, B. J. (2004). Defining spirit at work: Finding common ground. Journal of Organizational Change Management, 17, 26-42. http://dx.doi.org/10.1108/09534810410511288

Kline, R.B. (2005), Principles and Practice of Structural Equation Modeling (2nd Edition ed.). New York: The Guilford Press.

Kolodinsky, R. W., Giacalone, R. A., \& Jurkiewicz, C. L. (2008). Workplace values and outcomes: Exploring personal, organizational, and interactive workplace 
spirituality. Journal of Business Ethics, 81, 465-480. http://dx.doi.org/10.1007/ s10551-007-9507-0

Kouzes, J. M., \& Posner, B. Z. (1995). The leadership challenge: How to keep getting extraordinary things done in organizations. Foreword by Tom Peters. San Francisco: Jossey-Bass Publishers.

Krishnakumar, S., \& Neck, C. P. (2002). The "what", "why" and "how" of spirituality in the workplace. Journal of Managerial Psychology, 17, 153-164. http://dx.doi.org/ $10.1108 / 02683940210423060$

Kuchinke, K. P. (2013). Human agency and HRD: Returning meaning, spirituality, and purpose to HRD theory and practice. Advances in Developing Human Resources, 15, 370-381. http://dx.doi.org/10.1177/1523422313498563

Lane, H. W., \& Maznevski, M. L. (2014). International Management Behavior: Changing for A Sustainable World. ISBN: 1118527372. Cross Cultural Management. John Wiley \& Sons (siehe S. 118).

LePine, J. A., Erez, A., \& Johnson, D. E. (2002). The nature and dimensionality of organizational citizenship behavior: A critical review and meta-analysis. Journal of Applied Psychology, 87(1), 52-65. http://dx.doi.org/10.1037/00219010.87.1.52

Levering, R., \& Moskowitz, M. (1985). The 100 best companies to work for in America. New York, NY: New American Library

Liden, R. C., Wayne, S. J., Zhao, H., \& Henderson, D. (2008). Servant leadership: Development of a multidimensional measure and multi-level assessment. The 
Leadership Quarterly, 19, 161-177. http://dx.doi.org/10.1016/

j.leaqua.2008.01.006

Linder, M. (1989). The Employment Relationship in Anglo-American Law: A Historical Perspective.

Lips-Wiersma, M., \& Nilakant, V. (2008). Practical compassion: toward a critical spiritual foundation for corporate responsibility. In Spirituality in Business (pp. 51-72). Palgrave Macmillan US. http://dx.doi.org/10.1057/9780230611887_4

Lips-Wiersma, M., Dean, K. L., \& Fornaciari, C. J. (2009). Theorizing the dark side of the workplace spirituality movement. Journal of Management Inquiry, 18, 288300. http://dx.doi.org/10.1177/1056492609339017

Little, R. J., \& Rubin, D. B. (2014). Statistical analysis with missing data. John Wiley \& Sons.

MacKinnon, D. P., Lockwood, C. M., \& Williams, J. (2004). Confidence limits for the indirect effect: Distribution of the product and resampling methods. Multivariate behavioral research, 39(1), 99-128. http://dx.doi.org/10.1207/ s15327906mbr3901_4

Markus, H. R., \& Kitayama, S. (1991). Culture and the self: Implications for cognition, emotion, and motivation. Psychological review, 98(2), 224. http://dx.doi.org/ 10.1037/0033-295X.98.2.224

Marques, J., Dhiman, S., \& King, R. (2007). Spirituality in the workplace: What it is, why it matters, how to make it work for you. Fawnskin, CA: Personhozzod Press. 
Mayer, D. M., Kuenzi, M., Greenbaum, R., Bardes, M., \& Salvador, R. B. (2009). How low does ethical leadership flow? Test of a trickle-down model. Organizational behavior and human decision processes, 108, 1-13. 10.1016/j.obhdp.2008.04.002

Mayo, E. (1949). Hawthorne and the Western Electric Company: The social problems of an industrial civilisation. New York, NY: Routledge.

Miller, D. W. (2006). God at work: The history and promise of the faith at work movement. New York, NY: Oxford University Press.

Miller, D. W., \& Ewest, T. (2013). The present state of workplace spirituality: A literature review considering context, theory, and measurement/assessment. Journal of Religious \& Theological Information, 12, 29-54. http://dx.doi.org/10.1080/10477845.2013.800776

Miller, L. (1998, July 20). After their checkup for the body, some get one for the soul. The Wall Street Journal, pp. A1. Retrieved from http://www.wsj.com

Milliman, J., Czaplewski, A. J., \& Ferguson, J. (2003). Workplace spirituality and employee work attitudes: An exploratory empirical assessment. Journal of Organizational Change Management, 16, 426-447. http://dx.doi.org/10.1108/ 09534810310484172

Milliman, J., Ferguson, J., Trickett, D., \& Condemi, B. (1999). Spirit and community at Southwest Airlines: An investigation of a spiritual values-based model. Journal of organizational change management, 12(3), 221-233.

http://dx.doi.org/10.1108/09534819910273928

Mitroff, I. I., \& Denton, E. A. (1999, Summer). A study of spirituality in the workplace. Sloan Management Review, 83-91. Retrieved from http://sloanreview.mit.edu/ 
Moorman, R. H., \& Blakely, G. L. (1995). Individualism-collectivism as an individual difference predictor of organizational citizenship behavior. Journal of Organizational Behavior, 16, 127-142. http://dx.doi.org/10.1002/job.4030160204

Morse, N. C., \& Weiss, R. S. (1955). The function and meaning of work and the job. American Sociological Review, 20, 191-198. http://dx.doi.org/10.2307/2088325

Moxley, R. S. (2000). Leadership and spirit: Breathing new vitality and energy into individuals and organizations. San Francisco, CA: Jossey-Bass.

Myers, R. H. (2000). Classical and modern regression with applications (Duxbury Classic). Duxbury Press, Pacific Grove.

Naylor, T. H., Willimon, W. H., \& Österberg, R. (1996). The search for community in the workplace. Business and Society Review, 97, 42-47. Retrieved from http://onlinelibrary.wiley.com/journal/10.1111/(ISSN)1467-8594

Neal, J. A. (1997). Spirituality in management education: A guide to resources. Journal of Management Education, 21, 121-139. http://dx.doi.org/10.1177/ 105256299702100111

Neal, J. A., \& Bennett, J. (2000, Winter). Examining multi-level or holistic spiritual phenomena in the work place. Management, Spirituality, and Religion Newsletter, Academy of Management, 1-2. Retrieved from http://group.aomonline.org/msr/ newsletter.html

Nichols, M. (1994). Does new age business have a message for managers. Harvard business review, 72(2), 52-60. 
Nimon, K., \& Zigarmi, D. (2015). Development of the Work Intention Inventory ShortForm. New Horizons in Adult Education and Human Resource Development, 27(1), 15-28. http://dx.doi.org/10.1002/nha3.20090

Noer, D. M. (2009). Healing the wounds: Overcoming the trauma of layoffs and revitalizing downsized organizations (2nd ed., rev. ed.). Hoboken, NJ: Wiley.

Nord, W. R., Brief, A. P., Atieh, J. M., \& Doherty, E. M. (1990). Studying meanings of work: The case of work values. In A. P. Brief \& W. R. Nord (Eds.), Meanings of occupational work: A collection of essays (pp. 21-64). Lexington, MA: Lexington Books.

Nunnally, J. C., Bernstein, I. H., \& Berge, J. M. T. (1967). Psychometric theory (Vol. 226). New York: McGraw-Hi

O'Fallon, M. J., \& Butterfield, K. D. (2005). A review of the empirical ethical decisionmaking literature: 1996-2003. Journal of Business Ethics, 59, 375-413. http://dx.doi.org/10.1007/s10551-005-2929-7

O'Reilly, C. A., Chatman, J., \& Caldwell, D. F. (1991). People and organizational culture: A profile comparison approach to assessing person-organization fit. Academy of Management journal, 34(3), 487-516. http://dx.doi.org/10.2307/256404

Organ, D. W. (1977). A reappraisal and reinterpretation of the satisfaction-causesperformance hypothesis. Academy of Management Review, 2, 46-53. http://dx.doi.org/10.5465/AMR.1977.4409162

Organ, D. W. (1988). Organizational citizenship behavior: The good soldier syndrome. Lexington, MA: Lexington Books. 
Organ, D. W. (1997). Organizational citizenship behavior: It's construct clean-up time. Human Performance, 10(2), 85-97. http://dx.doi.org/10.1207/ s15327043hup1002_2

Organ, D. W., \& Ryan, K. (1995). A meta-analytic review of attitudinal and dispositional predictors of organizational citizenship behavior. Personnel Psychology, 48, 775802. http://dx.doi.org/10.1111/j.1744-6570.1995.tb01781.x

Oswick, C. (2009). Burgeoning workplace spirituality? A textual analysis of momentum and directions. Journal of Management, Spirituality \& Religion, 6, 15-25. http://dx.doi.org/10.1080/14766080802648615

Pandey, A., Gupta, R. K., \& Arora, A. P. (2009). Spiritual climate of business organizations and its impact on customers' experience. Journal of Business Ethics, 88, 313-332. http://dx.doi.org/10.1007/s10551-008-9965-z

Pargament, K. I. (1999). The psychology of religion and spirituality? Yes and no. The International Journal for the Psychology of Religion, 9(1), 3-16. http://dx.doi.org/10.1207/s15327582ijpr0901_2

Pawar, B. S. (2009). Some of the recent organizational behavior concepts as precursors to workplace spirituality. Journal of Business Ethics, 88, 245-261. http://dx.doi.org/ 10.1007/s 10551-008-9961-3

Pfeffer, J., \& Veiga, J. F. (1999). Putting people first for organizational success. The Academy of Management Executive, 13(2), 37-48. http://dx.doi.org/10.5465/ AME.1999.1899547 
Piccolo, R. F., Greenbaum, R., Den Hartog, D. N., \& Folger, R. (2010). The relationship between ethical leadership and core job characteristics. Journal of Organizational Behavior, 31(2-3), 259-278. http://dx.doi.org/10.1002/job.627

Podsakoff, N. P., LePine, J. A., \& LePine, M. A. (2007). Differential challenge stressorhindrance stressor relationships with job attitudes, turnover intentions, turnover, and withdrawal behavior: A meta-analysis. Journal of Applied Psychology, 92, 438-454. http://dx.doi.org/10.1037/0021-9010.92.2.438

Podsakoff, P. M., \& Organ, D. W. (1986). Self-reports in organizational research: Problems and prospects. Journal of Management, 12(4), 531-544. http://dx. doi.org/10.1177/014920638601200408

Podsakoff, P. M., MacKenzie, S. B., Moorman, R. H., \& Fetter, R. (1990). Transformational leadership behaviors and their effects on followers' trust in leader, satisfaction and organizational citizenship behaviors. The Leadership Quarterly, 1, 107-142. http://dx.doi.org/10.1016/1048-9843(90)90009-7

Porter, T. H., \& Norris, S. E. (2012). Workplace Spirituality: A Best Practice Toward Organizational Integrity. Integrity in Organizations: Building the Foundations for Humanistic Management, 429. http://dx.doi.org/10.1057/9781137280350_22

Ray, M. L., \& Rinzler, A. (Eds.). (1993). The new paradigm in business: Emerging strategies for leadership and organizational change. Los Angeles, CA: J. P. Tarcher.

Rego, A., \& Cunha, M. P. E. (2008). Workplace spirituality and organizational commitment: An empirical study. Journal of Organizational Change Management, 21, 53-75. http://dx.doi.org/10.1108/09534810810847039 
Rego, A., Cunha, M. P. E., \& Souto, S. (2007). Workplace spirituality, commitment, and self-reported individual performance: An empirical study. Management Research: Journal of the Iberoamerican Academy of Management, 5(3), 163-183. http://dx.doi.org/10.2753/JMR1536-5433050303

Roberts, T. P., \& Zigarmi, D. (2014). The impact of dispositional cynicism on jobspecific affect and work intentions. International Journal of Psychology, 49(5), 381-389. http://dx.doi.org/10.1002/ijop.12051

Robinson, S. L., \& Bennett, R. J. (1995). A typology of deviant workplace behaviors: A multidimensional scaling study. Academy of management journal, 38(2), 555-572. http://dx.doi.org/10.2307/256693

Roethlisberger, F. J. (1941). The Hawthorne experiments. In J. M. Shafritz, J. S. Ott, \& Y. S. Jang (Eds.), Classics of organization theory (7th ed., pp. 162-170). Boston, MA: Wadsworth.

Rose, K., Shuck, B., Twyford, D., \& Bergman, M. (2015). Skunked An Integrative Review Exploring the Consequences of the Dysfunctional Leader and Implications for Those Employees Who Work for Them. Human Resource Development Review. http://dx.doi.org 10.1177/1534484314552437

Ruggiero, V. R. (2015). Thinking critically about ethical issues (9 ed.).

Russell, R. F., \& Stone, A. G. (2002). A review of servant leadership attributes:

Developing a practical model. Leadership \& Organization Development Journal, 23, 145-157. http://dx.doi.org/10.1108/01437730210424 
Sama, L. M., \& Shoaf, V. (2008). Ethical leadership for the professions: Fostering a moral community. Journal of Business Ethics, 78(1-2), 39-46. http://dx.doi.org/ 10.1007/s10551-006-9309-9

Sambrook, S. (2012). Human and resource development is hard. Human Resource Development International, 15, 135-139. http://dx.doi.org/10.1080/ 13678868.2012 .663189

Sass, J. S. (2000). Characterizing organizational spirituality: An organizational communication culture approach. Communication Studies, 51(3), 195-217. http://dx.doi.org/10.1080/10510970009388520

Schermelleh-Engel, K., Moosbrugger, H., \& Müller, H. (2003). Evaluating the fit of structural equation models: Tests of significance and descriptive goodness-of-fit measures. Methods of psychological research online, 8(2), 23-74.

Schumacker, R., \& Lomax, R. (2010). A Beginner's Guide to Structural Equation Modeling. New York: Routledge.

Shadish, W. R., Cook, T. D., \& Campbell, D. T. (2002). Experimental and quasiexperimental designs for generalized causal inference. Boston, MA: Houghton Mifflin.

Shafranske, E. P., Malony, H. N. (1996). Religion and the clinical practice of psychology: A case for inclusion. In Dhafranske, E. P. (Ed), Religion and the clinical practice of psychology (pp. 561-586). Washington, DC, US: American Psychological Association. http://dx.doi.org/10.1037/10199-041 
Sheep, M. L. (2006). Nurturing the whole person: The ethics of workplace spirituality in a society of organizations. Journal of Business Ethics, 66, 357-375. http://dx.doi.org/10.1007/s10551-006-0014-5

Shrout, P. E., \& Bolger, N. (2002). Mediation in experimental and nonexperimental studies: new procedures and recommendations. Psychological methods, 7(4), 422. http://dx.doi.org/10.1037/1082-989X.7.4.422

Smith, B. N., Montagno, R. V., \& Kuzmenko, T. N. (2004). Transformational and servant leadership: Content and contextual comparisons. Journal of Leadership \& Organizational Studies, 10, 80-91. http://dx.doi.org/10.1177/ 107179190401000406

Smith, C. A., Organ, D. W., \& Near, J. P. (1983). Organizational citizenship behavior: Its nature and antecedents. Journal of Applied Psychology, 68, 653-663. http://dx.doi.org/10.1037/0021-9010.68.4.653

Sobel, M. E. (1982). Asymptotic confidence intervals for indirect effects in structural equation models. Sociological methodology, 13(1982), 290-312.

Sobel, M. E. (1986). Some new results on indirect effects and their standard errors in covariance structure models. Sociological methodology, 16, 159-186.

Sonnenfeld, J. A. (1985). Shedding light on the Hawthorne studies. Journal of Organizational Behavior, 6, 111-130. http://dx.doi.org/10.1002/job.4030060203

Steel, R. P., \& Ovalle, N. K. (1984). A review and meta-analysis of research on the relationship between behavioral intentions and employee turnover. Journal of Applied Psychology, 69, 673-686. http://dx.doi.org/10.1037/0021-9010.69.4.673 
Steger, M. F., Dik, B. J., \& Duffy, R. D. (2012). Measuring meaningful work: The Work and Meaning Inventory (WAMI). Journal of Career Assessment,20, 322-337. http://dx.doi.org/10.1177/1069072711436160

Steingard, D. S. (2005). Spiritually-informed management theory toward profound possibilities for inquiry and transformation. Journal of Management Inquiry, 14(3), 227-241. http://dx.doi.org/10.1177/1056492605276841

Stevens, B. (2008). Corporate ethical codes: Effective instruments for influencing behavior. Journal of Business Ethics, 78, 601-609. http://dx.doi.org/10.1007/ s10551-007-9370-z

SurveyMonkey. (n.d.). Need people to take your survey? (SurveyMonkey Audience). Retrieved November 6, 2015, from https://www.surveymonkey.com/mp/ audience/

SurveyMonkey. (2012). Data quality: Measuring the quality of online data sources [White paper]. Retrieved from http://www.slideshare.net/ SurveyMonkeyAudience/surveymonkey-audience-data-quality-whitepaperseptember-2012

SurveyMonkey. (2013). SurveyMonkey Audience's answers to the ESOMAR 28 questions. Retrieved from http://help.surveymonkey.com/servlet/ servlet.FileDownload?file $=01530000002 \mathrm{gvZ9}$

Tabachnick, B., \& Fidell, L. (2007). Using multivariate statistics (5th ed.). Needham Heights, MA, USA: Pearson Education.

Taylor, F. W. (1911). The principles of scientific management. New York, NY: Filiquarian. 
Tepper, B. J. (2010). Organizational citizenship behavior and the spiritual employee. In R. A. Giacalone \& C. L. Jurkiewicz (Eds.), Handbook of workplace spirituality and organizational performance (2nd ed., pp. 143-154). New York, NY: M. E. Sharpe.

Thompson, F., \& Perry, C. (2004). Generalising results of an action research project in one work place to other situations: Principles and practice. European Journal of Marketing, 38, 401-417. http://dx.doi.org/10.1108/03090560410518611

Tischler, L., Biberman, J., \& Altman, Y. (2007). A model for researching about spirituality in organizations. Business Renaissance Quarterly, 2(2), 23-39. Retrieved from http://www.brqjournal.com/

Treviño, L. K., Brown, M., \& Hartman, L. P. (2003). A qualitative investigation of perceived executive ethical leadership: Perceptions from inside and outside the executive suite. Human relations, 56(1), 5-37. http://dx.doi.org/10.1177/ 0018726703056001448

Treviño, L. K., Butterfield, K. D., \& McCabe, D. L. (1998). The ethical context in organizations: Influences on employee attitudes and behaviors. Business Ethics Quarterly, 8, 447-476. http://dx.doi.org/10.2307/3857431

U.S. Bureau of Labor Statistics (2016). Labor Force Statistics from the Current Population Survey. Retrieved from http://www.bls.gov/cps/cpsaat08.htm

U.S. Bureau of Labor Statistics (2016). Spotlight on Statistics: Percent distribution of self-employed by incorporation status, annual averages, 2015. Retrieved from http://www.bls.gov/spotlight/2016/self-employment-in-the-unitedstates/home.htm 
U.S. Bureau of Labor Statistics (2010). The Economics Daily: Work at home and in the workplace. Retrieved from http://www.bls.gov/opub/ted/2011/ted_20110624.htm (visited April 28, 2016).

Uprichard, E. (2013). Sampling: Bridging probability and non-probability designs. International Journal of Social Research Methodology, 16, 1-11. http://dx.doi.org/10.1080/13645579.2011.633391

Vardaman, J. M., Taylor, S. G., Allen, D. G., Gondo, M. B., \& Amis, J. M. (2015). Translating intentions to behavior: The interaction of network structure and behavioral intentions in understanding employee turnover. Organization Science, 26(4), 1177-1191. http://dx.doi.org/10.1287/orsc.2015.0982

Van der Walt, F., \& de Klerk, J. J. (2014). Workplace spirituality and job satisfaction. International Review of Psychiatry, 26, 379-389. http://dx.doi.org/10.3109/ 09540261.2014 .908826

Wulff, D. W. (1998). Rethinking the rise and fall of the psychology of religion. In. A. L. Molendijk and P. Pels (Eds.), Religion in the making: The emergence of the sciences of religion, (pp. 181-202). Leiden: Brill.

Yukl, G., Mahsud, R., Hassan, S., \& Prussia, G. E. (2013). An improved measure of ethical leadership. Journal of Leadership \& Organizational Studies, 20, 38-48. http://dx.doi.org/10.1177/1548051811429352

Zigarmi, D., Nimon, K., Houson, D., Witt, D., \& Diehl, J. (2012). The Work Intention Inventory: Initial evidence of construct validity. Journal of Business Administration Research, 1(1), 24-42. http://dx.doi.org/10.5430/jbar.v1n1p24 
Zinnbauer, B., \& Pargament, K. (2005). Religiousness and spirituality. In R. F. Paloutzian, CL Park (Eds.), Handbook of the psychology of religion and spirituality, (pp. 21-42) New York: Guilford. 


\section{APPENDICES}

\section{Appendix A}

Qualifying questions

1. Are you currently self-employed? (Self-employed individuals earn income through conducting profitable operations from a trade or business they operate directly, instead of working for an employer that pays a salary or wage).

Yes (ends survey)

No (proceeds to next question)

2. In a typical week, how many days do you work from home?

I don't work from home (proceeds to survey)

Once a week (proceeds to survey)

2 to 3 days a week (proceeds to survey)

4 to 5 days a week (ends survey) 


\section{Appendix B}

\section{Workplace Spirituality Measure*}

Please rate the following questions using the scale below:

$1=$ strongly disagree

$2=$ disagree

$3=$ somewhat disagree

$4=$ unsure

$5=$ somewhat agree

$6=$ agree

$7=$ strongly agree

Meaningful Work

1. I experience joy in my work.

2. My spirit is energized by my work.

3. The work I do is connected to what I think is important in life.

4. I look forward to coming to work most days.

5. My work adds personal meaning to my life.

Sense of Community

6. Working cooperatively with others is valued in my work environment.

7. I feel part of a community at work.

8. I believe people support each other in my work environment.

9. I feel free to express my opinions at work.

10. I believe employees are linked with a common purpose in my work environment. 11. I believe employees genuinely care about each other in my work environment.

12. I feel there is a sense of being part of a family in my work environment.

Alignment with Organizational Values

13. I feel positive about the values of my organization.

14. My current organization cares about whether my spirit is energized by my work.

15. My current organization is concerned about the poor in our community.

16. My current organization cares about all of its employees.

17. My current organization has a conscience: a high regard for morality and right conduct.

18. I feel connected with my organization's goals.

19. My current organization is concerned about the health of those who work here.

Note. * (Ashmos \& Duchon, 2000; Milliman et al., 2003) Adapted from "Spirituality at Work: A Conceptualization and Measure," by D. Ashmos and D. Duchon, 2000, Journal of Management Inquiry, 9, pp. 143-144. Copyright 2000 by Sage Publications. Adapted from "Workplace Spirituality and Employee Work Attitudes: An Exploratory Empirical Assessment," by J. Milliman, A. J. Czaplewski, and J. Ferguson, 2003, Journal of Organizational Change Management, 16, p. 437. Copyright 2003 by Emerald Group. 


\section{Appendix C}

\section{Work Intention Inventory Scale, Short Form*}

Please rate the following questions using the scale below:

$1=$ To no extent

$2=$ To a little extent

$3=$ To some extent

$4=$ Unsure

$5=$ To a great extent

$6=$ To a very great extent

$7=$ To the fullest extent

\section{Intent to Use Discretionary Effort}

1. I intend to volunteer for things that may not be a part of my job.

2. I intend to take work home if it makes me more effective the next day.

3. I intend to spend my discretionary time finding information that helps my organization.

Intent to Perform

4. I intend to exert the energy it takes to ensure I do my job well.

5. I intend to work efficiently to help my organization succeed.

6. I intend to achieve all of my work goals.

Intent to Endorse

7. I intend to talk positively about my organization to my family or friends.

8. I intend to speak out to project the reputation of my organization.

9. I intend to talk positively about the leadership of my organization.

Intent to Stay

10. I intend to continue to work for my current organization because I believe it is the best decision for me.

11. I intend to stay with my current organization even if I were offered a similar job with slightly higher pay elsewhere.

12. I intend to stay with my current organization even if I were offered a more appealing job with the same pay elsewhere.

Intent to Be an Organizational Citizen

13. I intend to respect this organization's assets.

14. I intend to consider the impact of my actions on others within in this organization.

15. I intend to watch out for the welfare of others in my work environment.

Note. * Adapted from "Development of the Work Intention Inventory Short-Form," by K. Nimon and D. Zigarmi, 2015, New Horizons in Adult Education and Human Resource Development, 27, p. 28. Copyright 2013 by Wiley. 


\section{Appendix D}

\section{Ethical Leadership Scale*}

Please use the following scale to rate each item:

$1=$ strongly disagree

$2=$ moderately disagree

$3=$ slightly disagree

$4=$ Unsure

$5=$ slightly agree

$6=$ moderately agree

$7=$ strongly agree

My current supervisor:

1. My current supervisor communicates clear ethical standards for members.

2. My current supervisor shows a strong concern for ethical and moral values.

3. My current supervisor sets an example of ethical behavior in his/her decisions and actions.

4. My current supervisor is honest and can be trusted to tell the truth.

5. My current supervisor keeps his/her actions consistent with his/her stated values ("walks the talk").

6. My current supervisor is fair and unbiased when assigning tasks to members.

7. My current supervisor can be trusted to carry out promises and commitments.

8. My current supervisor insists on doing what is ethical even when it is not easy.

9. My current supervisor acknowledges mistakes and takes responsibility for them.

10. My current supervisor regards honesty and integrity as important personal values.

11. My current supervisor sets an example of dedication and self-sacrifice for the organization.

12. My current supervisor opposes the use of unethical practices to increase performance.

13. My current supervisor is fair and objective when evaluating member performance.

14. My current supervisor puts the needs of others above his/her own self-interest.

15. My current supervisor holds members accountable for using ethical practices in their work.

Note. * Adapted from “An Improved Measure of Ethical Leadership,” by G. Yukl, R. Mahsud, S. Hassan, and G. E. Prussia, 2013, Journal of Leadership \& Organizational Studies, 20, p. 46. Copyright 2013 by Baker College. 


\section{Appendix E}

\section{Demographic Information}

1. What is your gender?
a. Female
b. Male
c. Other

2. What is your age?
a) $18-24$
b) $25-34$
c) $35-44$
d) $45-54$
e) 55-64
f) $>65$ or older

3. Which race/ethnicity best describes you?
a) American Indian or Alaskan Native
b) Asian / Pacific Islander
c) African American
d) Hispanic or Latino
e) White/Caucasian
f) Two or more

4. In a typical week, how many hours do you work at your primary job?
a) Less than 29 hours
b) 30 - 34 hours
c) $35-44$ hours
d) 45 - 59 hours
e) More than 60 hours

5. How long have you been in your current employer?
a) 1 to 3 years
b) 4 to 6 years
c) 7 to 9 years
d) 10 to 12 years
e) 13 to 15 years
f) More than 16 years

6. Last year, what was your total household income (from all sources and before taxes)?
a) $\$ 0$ to $\$ 24,999$
b) $\$ 25,000$ to $\$ 49,999$
c) $\$ 50,000$ to $\$ 74,999$
d) $\$ 75,000$ to $\$ 99,999$
e) $\$ 100,000$ to $\$ 124,999$
f) $\$ 125,000$ to $\$ 149,999$
g) $\$ 150,000$ to $\$ 174,999$ 

h) $\$ 175,000$ to $\$ 199,999$
i) $\$ 200,000$ to $\$ 224,999$
j) $\$ 225,000$ to $\$ 249,999$
k) $\$ 250,000$ and up

7. What is the highest level of school you have completed or the highest degree you have received?
a) Less than high school degree
b) High school degree or equivalent (e.g., GED)
c) Some college, but no degree
d) Associate's degree
e) Bachelor's degree
f) Graduate degree

8. Which of the following best describes your current job level?
a) Senior management
b) Mid-career
c) Intermediate
d) Entry level
e) Other

9. Which of the following best describes the principal industry of your organization?
a) Advertising \& Marketing
b) Agriculture
c) Airlines \& Aerospace (including Defense)
d) Automotive
e) Business Support \& Logistics
f) Construction, Machinery, and Homes
g) Education
h) Entertainment \& Leisure
i) Finance \& Financial Services
j) Food \& Beverages
k) Government
1) Healthcare \& Pharmaceuticals
m) Insurance
n) Manufacturing
o) Nonprofit
p) Retail \& Consumer Durables
q) Real Estate
r) Telecommunications, Technology, Internet \& Electronics
s) Transportation \& Delivery
t) Utilities, Energy, and Extraction
u) Other

10. For the purpose of this study, spirituality is defined as beliefs, practices, relationships, or experiences having to do with the sacred that are not necessarily linked to 
established institutionalized systems. In the context of this definition, do you consider yourself a spiritual person? Please rate yourself on a scale from 1 (not at all spiritual) to 5 (very spiritual).
a) Not at all spiritual
b) Slightly spiritual
c) Unsure
d) Moderately spiritual
e) Very spiritual

Please feel free to share any additional thoughts or comments (free response). 


\section{Appendix F}

\section{IRB Approval}

\section{UNIVERSITY OF LOUISVILLE}

Human Subjects Protection Program Office

MedCenter One - Suite 200

$501 \mathrm{E}$. Broadway

Louisville, KY 40202-1798

Office: 502.852.5188 Fax: 502.852.2164
DATE:

TO:

FROM:

IRB\#:

STUDY TITLE:

REFERENCE \#:

DATE OF REVIEW:

IRB STAFF CONTACT:
January 15, 2016

Brad Shuck, PhD

The University of Louisville Institutional Review Board

15.0620

Workplace Spirituality and Work Intentions: Examining the Relation and the Mediating Role of Ethical Leadership 447620

$01 / 15 / 2016$

Name: Jacqueline S. Powell, CIP

Phone: 852-4101

Email: jspowe01@Louisville.edu

This study was reviewed on 01/15/2016 and determined by the Vice-Chair of the Institutional Review Board that the study is exempt according to 45 CFR 46.101(b) under category 2: Research involving the use of educational tests (cognitive, diagnostic, aptitude, achievement), survey procedures, interview procedures or observation of public behavior unless, the information is obtained in an identifiable manner and any disclosure of the subjects responses outside of research could reasonably place the subject at risk..

This study was also approved through 45 CFR 46.117 (c), which means that an IRB may waive the requirement for the investigator to obtain a signed informed consent form for some or all subjects if it finds either:

-That the only record linking the subject and the research would be the consent document and the principal risk would be potential harm resulting from a breach of confidentiality. Each subject will be asked whether the subject wants documentation linking the subject with the research, and the subject's wishes will govern; or

- That the research presents no more than minimal risk of harm to subjects and involves no procedures for which written consent is normally required outside of the research context.

Documents/Attachments reviewed and approved:

\begin{tabular}{|l|l|l|l|}
\hline \multicolumn{4}{|l|}{ Submission Components } \\
\hline Protocol & Version 1.0 & $11 / 10 / 2015$ & Approved \\
\hline Preamble & Version 2.0 & $01 / 08 / 2016$ & Approved \\
\hline
\end{tabular}

Please be advised that any study documents submitted with this protocol should be used in the form in which they were approved. Since this study is exempt, the consent doesn't contain the IRB Approval stamp.

Since this study has been approved under the exempt category indicated above, no additional reporting, such as submission of Progress Reports for continuation reviews, is needed. If your research focus or activities change, please 
submit an Amendment to the IRB for review to ensure that the indicated exempt category still applies. Best wishes for a successful study. Please send all inquiries to our office email address at hsppofc@louisville.edu

Thank you for your submission.

Sincerely,

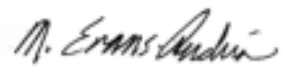

Melissa Evans Andris, PhD, Vice Chair

Social/Behavioral/Education Institutional Review Board

MEA/jsp

Full Acereditation since June 2005 by the Assoclation for the Acereditarian of Hwman Research Protection Programs, Inc.

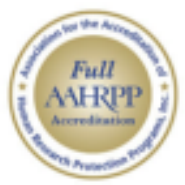




\section{Appendix G}

\section{Subject Informed Consent Document}

Research Study on Workplace Spirituality, Work Intentions, and Ethical Leadership

Dear colleague:

You are being invited to participate in a research study by answering an electronic survey about your perception of your experience in your work environment, your work intentions, and your perception of ethical behavior of your leaders. The purpose of this survey is to better understand how organizational variables such as workplace spirituality and ethical leadership affect your work intentions.

There are no known risks for your participation in this research study. The information collected may not benefit you directly however the information learned in this study may be helpful to others. The survey will take approximately 10-12 minutes to complete.

Individuals from the College of Education and Human Development at the University of Louisville, the Institutional Review Board (IRB) at the University of Louisville, the Human Subjects Protection Program Office (HSPPO), and other regulatory agencies may inspect these records. In all other respects, however, the data will be held in confidence to the extent permitted by law. Should the data be published, your identity will not be disclosed.

Taking part in this study is voluntary. By completing this survey you agree to take part in this research study. You do not have to answer any questions that make you uncomfortable. You may choose not to take part at all. If you decide to be in this study, you may stop taking part at any time. If you decide not to be in this study or if you stop taking part at any time, you will not lose any benefits for which you may qualify.

If you have any questions, concerns, or complaints about the research study, please contact: Brad Shuck, 502/852-7396.

If you have any questions about your rights as a research subject, you may call the Human Subjects Protection Program Office at the University of Louis ville at (502) 8525188. You can discuss any questions about your rights as a research subject, in private, with a member of the Institutional Review Board (IRB). You may also call this number if you have other questions about the research, and you cannot reach the research staff, or want to talk to someone else. The IRB is an independent committee made up of people from the University community, staff of the institutions, as well as people from the community not connected with these institutions. The IRB at the University of Louisville has reviewed this research study. 
If you have concerns or complaints about the research or research staff and you do not wish to give your name, you may call 1-877-852-1167. This is a 24-hour hotline answered by people who do not work at the University of Louisville.

To participate in this anonymous survey, simply click here:

https://www.surveymonkey.com/r/BBPX5TM

Sincerely,

Paula Soder

IRB assigned number:

Investigator(s) name: Brad Shuck, Ed.D \& Paula Soder, Doctoral Candidate, M.S., SPHR Phone number for subjects to call for questions: 502/852-7396 (Brad Shuck) 


\section{CURRICULUM VITA}

PAULA F. SODER

Fall 2016

Human Resources

University of California San Diego

10280 N. Torrey Pines Rd., Ste. 265A

5365 Toscana Way, Apt 4311

La Jolla, CA 92093

San Diego, CA

Phone: 858-534-1922

Phone: 805-903-2346

Email:psoder@ucsd.edu

Email:pfsoder@gmail.com

\section{EDUCATION}

\section{PhD in Educational Leadership and Organizational Development}

University of Louis ville, Louis ville, KY, Advisor: Dr. Brad Shuck Ed.D

\section{Master of Science in Industrial and Employee Relations}

Marshall University, Huntington, WV. May 2005

\section{Bachelor of Science, Letters, Language and Literature}

Universidade de Santa Cruz do Sul, RS Brazil. December 2002

\section{PROFESSIONAL EXPERIENCE}

2016 - $\quad$ Talent Acquisition Operations Manager

University of California - San Diego, Human Resources; La Jolla, CA

2015 - 2016 Adjunct Faculty, Management and Human Resources

Cal Poly - San Luis Obispo, Orfalea College of Business, San Luis

Obispo, CA

\section{9 - 2015 Manager of Employment Services}

University of Louisville, VP Human Resources; Louisville, KY

2008 - 2009 Policy and Budget Analyst

University of Louisville, VP Finance; Louisville, KY

2006 - 2008 Operations Supervisor, International Freight Specialist

UPS Supply Chain Solutions; Louisville, KY 
2001 - 2004 Instructor, Portuguese as a Foreign Language

Marshall University, Center for International Programs; Huntington, WV

2000 - 2001 Elementary and High School Teacher

Department of Education; Santa Cruz do Sul, Brazil

\section{PUBLICATIONS AND RESEARCH}

\section{Conference Proceedings}

Soder, P. \& Shuck, B. (2014). Workplace compassion: Strategic planning or disaster recovery. In D. Chapman (Ed.), Academy of Human Resource Development Conference Proceedings. Houston, TX: AHRD

Soder, P. \& Shuck, B. (2014). Workplace spirituality: A contribution to leadership and workplace theories. In D. Chapman (Ed.), Academy of Human Resource Development Conference Proceedings. Houston, TX: AHRD

Soder, P., Schneider, E., Vicentini, O. (1999). Leitura e Produção de Textos no $2^{\circ}$ Grau. In: V Seminário de Iniciação Científica/IV Jornada de Ensino, Pesquisa e Extensão, 1999, Santa Cruz do Sul, RS. Santa Cruz do Sul, RS : EDUNISC, 1999.

\section{Works in Progress}

Soder, P. (dissertation in preparation). Workplace spirituality and employee work intentions: examining the relationship and the mediating role of ethical leadership.

Soder, P. (manuscript in preparation). The changing nature of work: the art and science of workplace equality. (Submission target for Summer 2017).

\section{Research Interests}

- Theory building in HRM and HRD disciplines

- Personal and career impact of modern working practices

- Talent acquisition

- Organization development and change

- Ethics 